OPEN ACCESS

Edited by:

Maciej Harat,

Franciszek Lukaszczyk Oncology

Centre, Poland

Reviewed by:

Matthew Tate,

Northwestern University, United States

Eng-Siew Koh,

University of New South

Wales, Australia

*Correspondence:

Aurélie Moreau

aurelie.moreau@lyon.unicancer.fr

Specialty section:

This article was submitted to

Neuro-Oncology and Neurosurgical

Oncology,

a section of the journa

Frontiers in Oncology

Received: 30 April 2019 Accepted: 10 October 2019 Published: 01 November 2019

Citation:

Moreau A, Febvey O, Mognetti T, Frappaz D and Kryza D (2019)

Contribution of Different Positron Emission Tomography Tracers in Glioma Management: Focus on Glioblastoma. Front. Oncol. 9:1134. doi: 10.3389/fonc.2019.01134

\section{Contribution of Different Positron Emission Tomography Tracers in Glioma Management: Focus on Glioblastoma}

\author{
Aurélie Moreau ${ }^{1 *}$, Olivia Febvey ${ }^{1}$, Thomas Mognetti ${ }^{1}$, Didier Frappaz ${ }^{1}$ and David Kryza ${ }^{2,3}$ \\ ${ }^{1}$ Centre Léon Bérard, Lyon, France, ${ }^{2}$ UNIV Lyon - Université Claude Bernard Lyon 1, LAGEPP UMR 5007 CNRS \\ Villeurbanne, Villeurbanne, France, ${ }^{3}$ Hospices Civils de Lyon, Lyon, France
}

Although rare, glioblastomas account for the majority of primary brain lesions, with a dreadful prognosis. Magnetic resonance imaging (MRI) is currently the imaging method providing the higher resolution. However, it does not always succeed in distinguishing recurrences from non-specific temozolomide, have been shown to improve -related changes caused by the combination of radiotherapy, chemotherapy, and targeted therapy, also called pseudoprogression. Strenuous attempts to overcome this issue is highly required for these patients with a short life expectancy for both ethical and economic reasons. Additional reliable information may be obtained from positron emission tomography (PET) imaging. The development of this technique, along with the emerging of new classes of tracers, can help in the diagnosis, prognosis, and assessment of therapies. We reviewed the current data about the commonly used tracers, such as 18F-fluorodeoxyglucose (18F-FDG) and radiolabeled amino acids, as well as different PET tracers recently investigated, to report their strengths, limitations, and relevance in glioblastoma management.

Keywords: glioblastoma, imaging, PET, FDG, DOPA, radiolabeled amino acids, PSMA

\section{INTRODUCTION}

Gliomas are the most common primary malignant brain tumors arising from glial cells. The glial cells form the neuronal environment and are involved in myelin production and in the support and protection of the neurons. A new World Health Organization (WHO) classification has been proposed recently, combining the gliomas both from histological and molecular findings and classifying them into four grades (1). Glioblastomas are the most frequent type of gliomas in adults (about 55\%), with an increasing annual incidence of 3-4 per 100,000 people newly diagnosed in the USA and Europe. The disease is slightly more frequent in males than in females. They are particularly locally aggressive, with rare cases of metastases. The prognosis is dismal with a 5 -year survival rate of lower than $10 \%(2,3)$. According to the 2016 WHO classification, two main subtypes of glioblastomas are identified: the isocitrate dehydrogenase (IDH)-wildtype and the IDH-mutant variants. The IDH mutation leads to a D2-hydroxyglutamate overproduction, involved in a large number of cellular reactions and in histone and DNA hypermethylation $(4,5)$. Primary or de novo glioblastoma is frequently characterized by the presence of the IDH-wildtype isoform in $\sim 90 \%$ of cases, occurring in older patients. The other $10 \%$ with the IDH-mutant 
variant is seen in younger patients with secondary glioblastoma, with a prior history of lower grade diffuse glioma (1). The risk factors currently identified are the exposure to therapeutic doses of radiation and genetic syndromes (such as neurofibromatosis 1 and 2 and the Li-Fraumeni syndrome) (6). Clinical symptoms include headaches, epileptic seizures, focal neurologic deficit, confusion, memory loss, and personality modifications, depending on the location of the tumor (7). The gold standard treatment is surgical resection, radiotherapy, and chemotherapy $(8,9)$. Although complete surgical resection of glioblastomas is often not achievable due to their highly infiltrating nature, the extent of surgical resection remains a key component for survival improvement (10-12). The second cornerstone is subsequent radiation therapy that can lead to an improvement in survival rate of 6 months (13). For patients up to 71 years, the standard treatment is adjuvant administration of temozolomide chemotherapy treatment, leading to an improvement in progression-free survival (PFS) and overall survival (OS) (14). All patients with a 2.5 months global survival benefit are eligible (15). However, a better efficacy is observed in patients with a methylated MGMT promoter $(3,16)$. Targeted therapies, such as the anti-VEGF agent bevacizumab in association with temozolomide, have been shown to improve PFS, but no impact on OS has been reported $(17,18)$. Despite the initiation of such aggressive treatments, relapses are the rule. The reference imaging technique to monitor the onset of recurrences is magnetic resonance imaging (MRI), more specifically, multimodal MRI (MRI with gadolinium injection associated with spectroscopy, perfusion, and diffusion). Glioblastomas conventionally appear as hypo or iso-intense on T1, enhanced in "a ring pattern" in T1 with gadolinium, and are hyper-intense on $\mathrm{T} 2$ and FLAIR acquisitions. The challenge is to improve diagnosis and to discriminate post-therapeutic recurrences from radiation complications, such as pseudoprogression or radiation necrosis, and from pseudoresponse.

Pseudoprogression can be defined as a subacute radiationrelated side effect. It occurs after radiotherapy, particularly with high-dose delivery or with associated chemotherapy, occurring in the first 3 months after radiotherapy, or later, making identification and diagnosis difficult. This concerns about $20 \%$ of patients, with an incidence twice higher in patients with glioblastoma harboring a methylation of the MGMT promoter for which the prognosis is better. The pathophysiology is not well-understood, and some neurological symptoms may be associated. Spontaneous resolution is generally observed within a few weeks or months. No specific treatment is needed $(19,20)$, and these patients are therefore at risk of inappropriate further treatment. Radiation necrosis is a later and chronic inflammation radiation-related complication. This brain tissue injury occurs at least 3 months after completing radiotherapy, with a reported incidence from 5 to $40 \%$ (21). Clinical symptoms and imaging features may mime a relapse. Radiation necrosis lesions may be associated with recurrence lesions, making it difficult to diagnose conclusively (22). Biopsy is the gold standard but may not be feasible or may be inconclusive due to a limited and nonrepresentative sampling. Furthermore, this invasive procedure may lead to further damage. Proposed treatments include steroids, bevacizumab, surgical resection, anticoagulation, or hyperbaric oxygen therapy.

Pseudoresponse is defined as an important diminution in contrast enhancement within the first two days after antiangiogenic therapies initiation. It is an indirect effect of treatment on vascular permeability but does not reflect a real antitumor effect $(23,24)$. The Macdonald criteria published in 1990 are based on the evaluation of tumor size measured on contrast enhancement (25). However, contrast enhancement is non-specific, reflecting only the extravasation of gadolinium through the disrupted blood-brain barrier (BBB). These response assessment in neuro-oncology (RANO) criteria added T2 and FLAIR modifications to contrast enhancement to evaluate tumor response (26). RANO has recently evolved into RANO modified and RANO in immunotherapy to take into account new treatments, such as targeted therapies and immunotherapy, and to allow standardized comparison in clinical trials $(27,28)$. Regardless of the evaluation criteria used, MRI techniques have some limitations, especially the confusion caused by treatmentinduced modifications, such as radiation therapy, bevacizumab, or even corticosteroids that induce tumor shrinkage (29). More effective tools are needed to overcome these drawbacks and bring relevant additional information.

Functional nuclear imaging may investigate metabolismrelated changes for oncological response assessment (30). Many positron emission tomography (PET) tracers have been studied, such as ${ }^{18}$ F-FDG (which explores glucose metabolism), the nucleoside analog ${ }^{18} \mathrm{~F}$-fluorothymidine $\left({ }^{18} \mathrm{~F}\right.$-FLT), radiolabeled amino acids such as ${ }^{18} \mathrm{~F}$-fluorodihydroxyphénylalanine $\left({ }^{18} \mathrm{~F}\right.$ FDOPA), ${ }^{18} \mathrm{~F}$-fluoro-ethyl-tyrosine $\left({ }^{18} \mathrm{~F}\right.$-FET), ${ }^{11} \mathrm{C}$-methionine $\left({ }^{11} \mathrm{C}-\mathrm{MET}\right)$, and hypoxia tracers such as ${ }^{18} \mathrm{~F}$-fluoromisonidazole (18F-FMISO) (Figure 1). These different tracers can provide additional reliable data in equivocal situations, guide a biopsy, help plan the tumoral volume delineation before radiotherapy, detect early tumor recurrence, distinguish pseudoprogression from relapse, evaluate response early during treatment (especially with new targeted treatments), and have prognostic value. Here, we detail the contributions that these tracers provide and we explore the opportunites that new tracers currently under evaluation may provide beyond routinely used tracers.

As explained above, the two major problems we are currently facing are the early distinction of tumor recurrence from posttherapeutic complications as well as the predictive response to targeted treatment. They imply both ethical and medicoeconomics issues, avoiding to inadequately discontinue an effective treatment or maintain an ineffective treatment.

\section{CARBOHYDRATE METABOLISM TRACER: ${ }^{18}$ F-FDG}

The 2-deoxy-2-fluoro-D-glucose is a glucose analog used by tumors cells overexpressing GLUT1 and GLUT3 transporters in malignancies and is the most commonly used PET tracer in tumor assessment. After active transportation across the BBB, it is captured by the cells and phosphorylated as the first step of the Krebs cycle, preventing further release. 


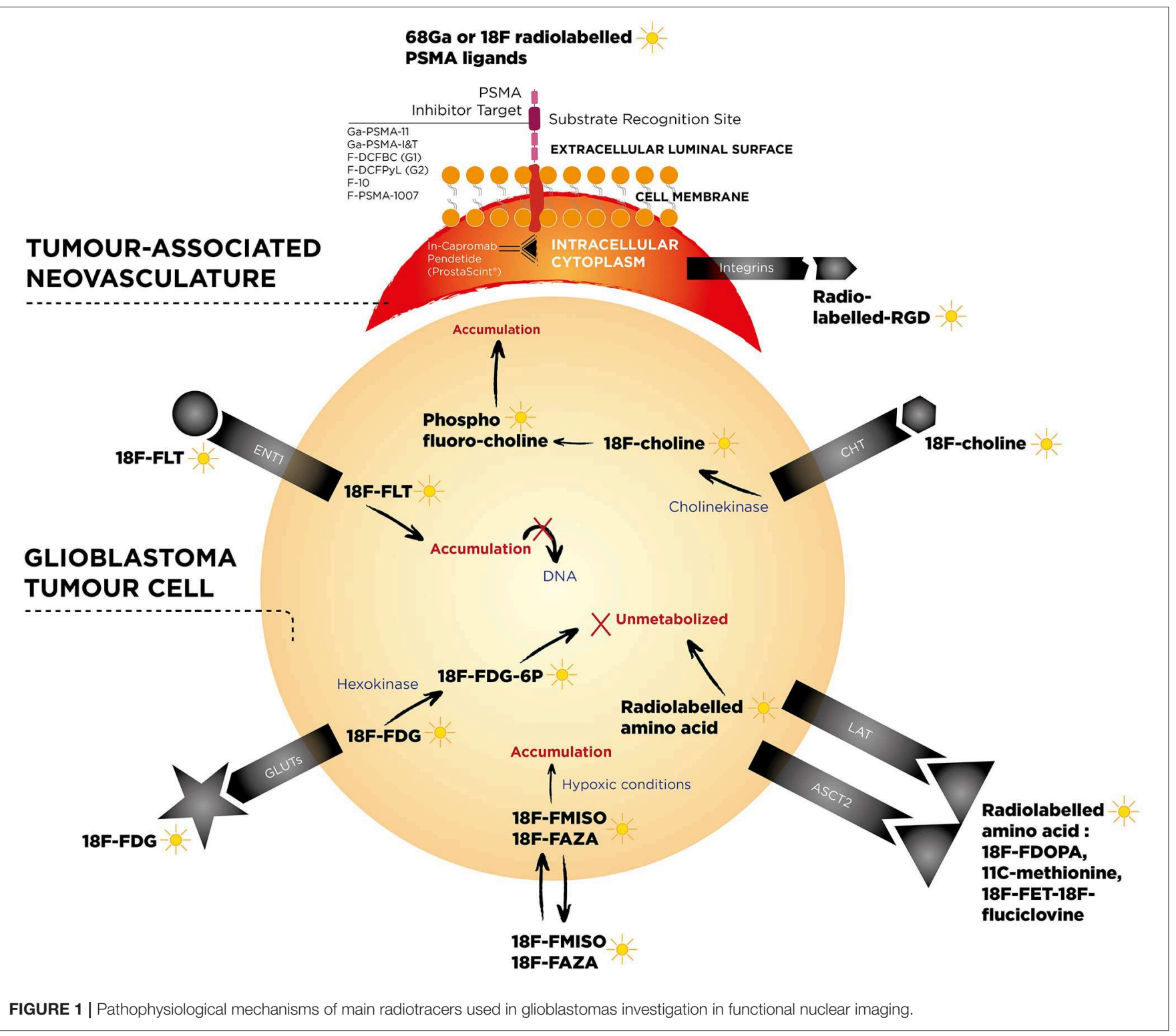

Despite its interesting role in differentiating low-grade from high-grade gliomas, no reliable cutoff level has been able to characterize brain tumors. The cutoff that Delbeke et al. proposed was not confirmed in semiquantitative analysis because of a large overlap between tumor standard uptake value (SUV)max and healthy parenchyma contralateral brain SUVmax (31-33). Furthermore, potential false positives, such as granulomatous diseases (tuberculosis or sarcoidosis), pyogenic abscesses, fungal infections, or other primary brain tumors, such as primary brain lymphomas, limited its role in initial and differential diagnosis (34-36).

It could however help in guiding the biopsy by highlighting the most hypermetabolic tumor area (37).

Its performances in discriminating radiation necrosis from tumor relapse are still debated (21). Assumptions for the use of ${ }^{18} \mathrm{~F}$-FDG were based on an increase in metabolic rate in tumor recurrence, theoretically leading to a hot spot, compared to supposedly reduced metabolic rate in radiation necrosis leading to a cold spot (38). Initial studies reported strong performances (39-41), but the specificity varies greatly from one study to another (40-94\%), while the sensitivity remains rather consistent (81-86\%) (21). These differences could be explained by heterogeneity in the type of radiation, tumor heterogeneity or subtypes, and the timing of the PET examination after radiotherapy (29).

However, these encouraging performances have been revised downward. A study including the results of ${ }^{18} \mathrm{~F}-\mathrm{FDG}$ PET vs. stereotactic biopsy demonstrated sensitivity and specificity of 43 and $100 \%$, respectively, in the differentiation between recurrence and radiation necrosis (42). Indeed, PET interpretation based on the detection of an abnormal hypermetabolic or hypometabolic spot compared with the 
surrounding area or the contralateral equivalent tissue is challenging. The high physiological brain uptake limits brain tumor detection. False-positive lesions-inflammation, abscesses, foci of gliosis-and false-negative lesions, such as cerebral necrosis, limits reliability (43). Another issue is the frequent association of radiation necrosis with residual lesions (39). ${ }^{18} \mathrm{~F}$-FDG is therefore disappointing in resolving this thorny issue (44). The utility of ${ }^{18} \mathrm{~F}-\mathrm{FDG}$ would lie in the exploration of enhanced lesions on MRI to eliminate a differential diagnosis when clinical symptoms and MRI are discordant. A hypometabolic feature would allow the patient to be freed from biopsy or new treatments and would allow a simple follow-up (45).

Its prognostic and predictive roles are less controversial and better assessed. It is a recognized prognostic tool, regardless of its schedule in follow-up (46-48).

It is a significant independent prognostic factor for high-grade glioma before treatment (49) as well as an important predictive factor of survival in patients with suspicion of glioma relapse (50).

A ratio of 2.0 or 2.5 between the residual lesion SUVmax and the healthy white matter SUVmax could be used as a cutoff to identify patients with reduced survival who may potentially benefit from other therapeutic strategies (51).

Early changes in the glucose metabolic rate predicted response to temozolomide but failed to predict response to temozolomide plus radiotherapy (52). In treatment with bevacizumab and irinotecan, ${ }^{18} \mathrm{~F}$-FDG is a predictive biomarker of response to treatment, with an uptake correlated with survival to a greater extent than any other prognostic factor tested (53).

Its role in tumor delineation is limited by its lack of specificity, other tracers have a better performance in this indication (Figure 2) (54).

Dose escalation in radiation therapy, based on the ${ }^{18} \mathrm{~F}$ FDG uptake, led to an additional boost in the hypermetabolic tumor areas. Although no additional toxicity was reported, this dose escalation did not improve PFS or OS in comparison to institutional historical series. Most recurrences occurred at sites that received the irradiation boost (55).

Several points have been stressed to improve PET with ${ }^{18} \mathrm{~F}-\mathrm{FDG}$ in this disease. Delayed examinations could increase the examination performances by enhancing the tumor-tonormal brain uptake contrast. A better discrimination of tumors compared to the surrounding gray substance was reached on late images performed at $180-480 \mathrm{~min}$ both on visual and semiquantitative analysis. Imaging at $300 \mathrm{~min}(5 \mathrm{~h})$ allowed an $18 \%$ increase in the tumor/gray matter ratio ( $\mathrm{T} / \mathrm{G}$ ratio). This could result from an improved degradation of ${ }^{18}$ F-FDG-6phosphate in the normal cerebral parenchyma compared to the tumor. However, performing such delayed images in current clinical practice is rarely feasible (56).

It is of paramount importance to perform MRI to compare information. Hybrid PET/MRI could better allow to discriminate radiation necrosis from tumor recurrence by combining the PET parameters and MRI perfusion parameters (29, 57-59). The composite association of the apparent diffusion coefficient (ADC) on diffusion MRI with SUVmax/normal brain ratio on PET could also allow the identification of patients at risk of progression. Those with an $\mathrm{ADC} \leq 1.400 \times 10^{-5} \mathrm{~mm}^{2} / \mathrm{s}$ and with a SUVmax/Normal brain index $>1.5$ would be most at risk of tumor progression (60). Other authors reported that tumor cross-product and metabolic tumor volume (MTV) on PET at time of first recurrence were significantly correlated with survival (61).

\section{CELL MEMBRANE METABOLISM: ${ }^{18} \mathrm{~F}$-FLUOROCHOLINE AND ${ }^{11} \mathrm{C}$-CHOLINE}

Choline is a metabolite incorporated into cancer cell's membrane, which therefore reflects cellular membrane metabolism through its incorporation in different choline-transporting transmembrane systems, such as high-affinity choline transporters (CHTs), choline transporter-like proteins (CTLs), organic cation transporters (OCTs), and organic cation/carnitine transporters (OCTNs), and through the upregulation of choline kinase metabolizing choline to phosphatidylcholine. It can be radiolabeled with either ${ }^{18} \mathrm{~F}$ or ${ }^{11} \mathrm{C}(62)$.

${ }^{11} \mathrm{C}$-choline is used to differentiate high-grade from lowgrade gliomas but low-grade gliomas and non-neoplastic lesions failed to be distinguished (63). In single lesions enhanced on MRI, the uptake of ${ }^{18} \mathrm{~F}$-fluorocholine was significantly higher in high-grade gliomas compared with benign lesions with SUVmax lesions $(1.89 \pm 0.78)$ vs. $(0.59 \pm 0.31)$, respectively $(p<0.0001)$. The increased uptake in the peritumoral area was characterized high-grade gliomas (64). However, investigations on malignant and non-malignant lesions from brain and other locations showed that uptake may occur in lesions other than malignant ones, and recommended caution in interpreting results (65). For example, benign lesions, such as tumefactive demyelination and radiation-induced mass, may be the site of moderate to significant ${ }^{18} \mathrm{~F}$-fluorocholine uptake (66).

${ }^{18} \mathrm{~F}$-Fluorocholine may be useful in differentiating tumor recurrence from radiation necrosis. There is a very low uptake in acute radiation necrosis in rats based on disruption of the $\mathrm{BBB}$ and uptake by inflammatory cells, especially macrophages. In humans, radiation necrosis differs because dose and type of irradiation are obviously different, and the onset of a chronic phase of radiation injury is frequently observed, but the use of ${ }^{18} \mathrm{~F}$-fluorocholine is nevertheless considered (67) and reinforced with results obtained from 55 patients with suspected brain tumor recurrence or radiation necrosis after radiation therapy, including initial grade-IV gliomas. ${ }^{11} \mathrm{C}$-choline exceeded the performance of ${ }^{18} \mathrm{~F}-\mathrm{FDG}$, with sensitivity and specificity of 92.3 and $76.9 \%$, and $87.5 \%$ and $62.5 \%$, respectively. However, histologic confirmation was performed in only a few patients. In addition, two false positives-gliosis and post-radiation granuloma-and three false negatives were reported, including two negative glioblastomas attributed to a too short delay after the end of radiotherapy (68).

\section{RADIOLABELED AMINO ACID}

Amino acid incorporation into membrane transporters is upregulated in tumor cells, regardless of the permeability of the 


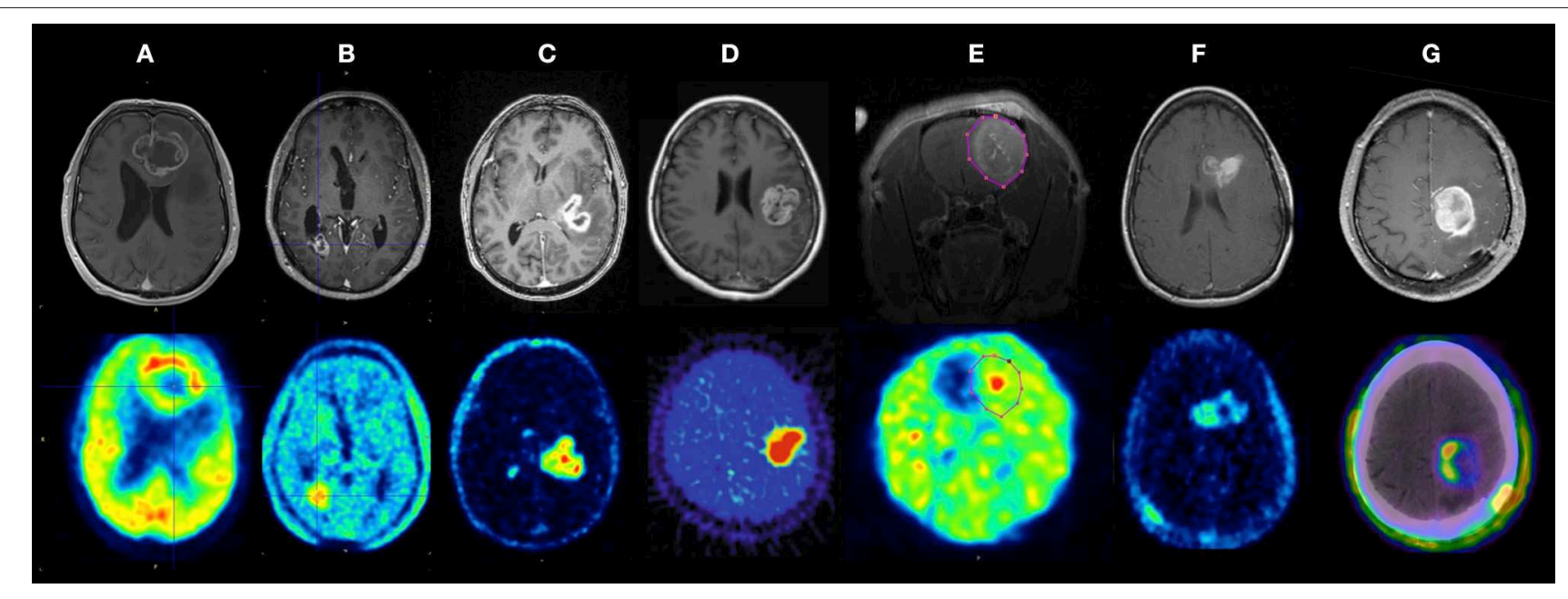

FIGURE 2 | Contrast-enhanced MRI (top row) and multiple PET tracers (bottom row) in glioblastoma. (A) ${ }^{18} \mathrm{~F}$-fluorodeoxyglucose $\left({ }^{18} \mathrm{~F}\right.$-FDG), (B)

${ }^{18} \mathrm{~F}$-fluoroethyltyrosine $\left({ }^{18} \mathrm{~F}\right.$-FET), (C) ${ }^{18} \mathrm{~F}$-fluoromethylcholine $\left({ }^{18} \mathrm{~F}\right.$-FCho), (D) ${ }^{18} \mathrm{~F}$-fluoromisonidazole $\left({ }^{18} \mathrm{~F}\right.$-FMISO) PET in human glioblastoma, (E) ${ }^{18} \mathrm{~F}$-fluoroazomycin arabinoside ( ${ }^{18} \mathrm{~F}$-FAZA) PET of the rat F98 model, (F) ${ }^{18} \mathrm{~F}$-fluorothymidine ( $\left.{ }^{18} \mathrm{~F}-\mathrm{FLT}\right)$ PET, and (G) ${ }^{18} \mathrm{~F}-\mathrm{AlF}-\mathrm{NOTA}$-PRGD2 (18F-RGD) PET/CT in human GB. Bolcaen et al. (54). Used with permission from the publisher.

BBB. Their contribution can outperform the conventional and ${ }^{18}$ F-FDG limitations and drawbacks, in particular for contentious cases (69). The intense uptake in tumors and weak capture in the normal brain provide a higher contrast and better delineation between tumors and healthy surrounding tissue (29). The nonspecific increase in amino acid results from enhanced energy requirements, increased cell division and protein synthesis, associated with specific oncogenic modifications in the targeted membrane transporters (70). An increased expression of receptors in the vasculature of tumor lesions also contributed to amino acid uptake (71). The use of radiolabeled amino acids, mainly ${ }^{11} \mathrm{C}$-methionine, ${ }^{18} \mathrm{~F}$-FDOPA, and ${ }^{18} \mathrm{~F}$-FET in gliomas, and more specifically glioblastomas, is actively being investigated. The RANO working group and the European Association for Neuro-Oncology published recommendations for the use of these PET tracers in routine clinical practice to differentiate neoplastic and non-neoplastic lesions, define tumor extent before surgical resection, evaluate the quality of resection with postoperative control and search for tumor residue, determinate biopsy site, assess prognosis before or after treatment, determine MTV as part of radiotherapy planning, perform therapeutic evaluation of adjuvant treatments, differentiate post-therapeutic modifications and tumor recurrence, and monitor adjuvant therapy (69-72).

\section{${ }^{11} \mathrm{C}-M E T H I O N I N E$}

The first radiolabeled amino acid explored was ${ }^{11} \mathrm{C}$-methionine, however, the short half-life of $20 \mathrm{~min}$ for ${ }^{11} \mathrm{C}$ restricts its use to the rare facilities with on-site cyclotron.

Contrary to ${ }^{18}$ F-FDG, which does not allow benign lesions to be differentiated from malignant lesions in the case of isoor hypo-metabolic lesions, performances for ${ }^{11} \mathrm{C}$-methionine are excellent (sensitivity and specificity of 89 and $100 \%$, respectively). Moreover, ${ }^{11} \mathrm{C}$-methionine binding correlates with the proliferation index (73).

${ }^{11} \mathrm{C}$-methionine allows the distinction between low-grade and high-grade tumors. Lopci et al. showed a more intense ${ }^{11} \mathrm{C}$-methionine uptake in primary glioblastoma compared to other gliomas. The captation significantly correlated with IDH1 mutation status in the majority of gliomas, with the exception of glioblastomas (74).

It may a good substitute for ${ }^{18} \mathrm{~F}-\mathrm{FDG}$ in guiding stereotactic biopsy owing to better performances in sensitivity and specificity, especially in lesions with no ${ }^{18} \mathrm{~F}$-FDG uptake or uptake less than or equal to that of gray matter $(75,76)$.

Conflicting results remain in differentiating between radiation necrosis and tumor recurrence. ${ }^{11} \mathrm{C}$-methionine was first identified as better than ${ }^{18} \mathrm{~F}-\mathrm{FDG}$ and ${ }^{11} \mathrm{C}$-choline (77). However, Kim et al. failed to prove a significant difference in discriminating radiation necrosis from tumor recurrence. The uptake in a radiation necrosis lesion may result from an increased methionine metabolism and permeability induced by reactive gliosis after radiation injury, an accumulation in glial cells proliferating in the area of radiation necrosis and $\mathrm{BBB}$ modifications (78).

It allows the refining of irradiation and reirradiation planning. It may help identify areas at high risk of recurrence that may benefit from a radiation boost. The fusion of PET with ${ }^{11} \mathrm{C}$-methionine, computed tomography (CT), and MRI results could be a potential tool in the reirradiation of glioblastoma recurrences. The target volume delineation may be improved by better discriminating post-therapeutic modifications of tumor zones to spare healthy tissues and thus improve the therapeutic ratio $(79,80)$. This fusion-based radiation planning significantly improved the survival in reirradiated patients compared with patients for whom radiation planning was based on CT/MRI alone (81). 
It contributes to the management of patients undergoing treatment with temozolomide. A small series reported that tumor response could be evaluated after three cycles of chemotherapy, with the absence of progression correlated with tracer uptake stability during the next three cycles. The stable or decreased uptake on metabolic imaging was consistent with clinical stability. A decreased uptake was associated with a significantly longer time to progression (TTP) compared with increased uptake (82). ${ }^{11}$ C-MET-PET at 8 weeks allowed identification of responders with significantly longer PFS than non-responders (83).

Wider use of ${ }^{11} \mathrm{C}$-methionine is nonetheless limited by the need for an on-site cyclotron. Other radiolabeled amino acids have therefore been explored to overcome this restriction.

\section{${ }^{18}$ F-FDOPA}

${ }^{18}$ F-FDOPA was initially used to assess the distribution of dopamine in patients with movement disease as a precursor to dopamine entering into brain tumors through the L-type amino acid transporter (LAT), without significant uptake in the surrounding brain parenchyma, except the basal ganglia (84). The potential interest in ${ }^{18} \mathrm{~F}$-FDOPA in the exploration of brain tumors was first reported by accidentally discovering a grade II oligo-astrocytoma with ${ }^{18} \mathrm{~F}$-FDOPA in a patient with movement disorders and suspicion of underlying Parkinson's disease (85).

${ }^{18} \mathrm{~F}$-FDOPA uptake is significantly associated with LAT1 expression, but the linear correlation between the LAT-1 expression level and the intensity of fixation is still debated (86, 87). ${ }^{18} \mathrm{~F}$-FDOPA transported into tumor cells does not remain trapped. The permeability of the BBB could have an additional and complementary effect and may be added to the increased expression of amino acid carriers in high-grade tumors (88).

${ }^{18}$ F-FDOPA combines the successful biopharmacological properties of amino acids and the convenient physical and logistical properties of fluorine 18. It could replace ${ }^{11} \mathrm{C}$ methionine in amino acid transport imaging in glioblastomas. Visual analyses and SUV ratios of ${ }^{18} \mathrm{~F}$-FDOPA compared with ${ }^{11} \mathrm{C}$-methionine suggest that it is an excellent surrogate for the exploration of recurrent lesions, especially for centers without on-site cyclotron. ${ }^{18}$ F-FDOPA may assist in grading newly diagnosed gliomas, in planning radiotherapy, and in assessing treatment response (89). Another advantage is the possibility of acquiring images as early as $20 \mathrm{~min}$ after injection, without hindrance from the delayed basal ganglia physiological fixation, which peaks later $(85,90,91)$.

18F-FDOPA is used to discriminate high grades from low grades. 18F-FDOPA uptake prior to the treatment of newly diagnosed glioma has been reported to correlate with tumor grade and proliferation. No significant correlation was reported in recurrent gliomas (92). The correlation between uptake and tumoral aggressiveness can help in the distinction of lowand high-grade tumors, according to enhancement. Distinct, although close, SUVmax thresholds have been reported (92, 93). It should be noted that glioblastoma tumor uptake may sometimes be less intense than oligodendroglioma uptake (94).
Janvier and collaborators highlighted that other indices, such as the SUVmean tumor/normal brain ratio or the SUVmean tumor/striatum ratio could allow a better discrimination between low- and high-grade tumors in routine practice (93). ${ }^{18} \mathrm{~F}$-FDOPA kinetics and capture revealed differences between high- and lowgrade tumors, notably differences in time-activity curves. Highgrade tumor profiles showed an early maximum followed by a steep decrease, whereas low-grade tumors showed a slowly declining curve (88). Conversely, some rare studies failed to demonstrate a difference in ${ }^{18} \mathrm{~F}$-FDOPA uptake between lowgrade and high-grade gliomas $(95,96)$, possibly related to limited statistical power and differences in examination time and duration for image acquisition.

18F-FDOPA to guide the biopsy site: the intensity of uptake is related to the grade. Hence, 18F-FDOPA could identify highgrade areas and could determine sites that could benefit from radiotherapy boost (97).

However, 18F-FDOPA in planning radiotherapy was disappointing. It allowed broader tumor delineation and significantly wider contour of the gross tumor volume (GTV) than that defined with MRI alone; however, the therapeutic impact was low as almost all relapses occurred outside the PET-GTV $(98,99)$.

${ }^{18} \mathrm{~F}$-FDOPA is very useful for distinguishing radiation necrosis and glioblastoma recurrence $(100,101)$. Visual analysis based on a 5-point visual scale or semiquantitative images analysis using lesion-to-striatum or lesion-to-normal brain tissue were accurate in distinguishing recurrence from treatment-related changes in 110 patients followed for glioblastoma and were prognostic of PFS. Patients with positive examinations had a 4.2 times shorter median OS than patients with negative examinations (101).

The superiority of ${ }^{18} \mathrm{~F}$-FDOPA over ${ }^{18} \mathrm{~F}$-FDG is reported in the recurrent tumor evaluation and in the differentiation between tumor recurrence and radiation necrosis, thanks to a higher contrast between tumor tissue and normal tissue. Sensitivity of ${ }^{18}$ F-FDOPA was higher than ${ }^{18}$ F-FDG on visual analysis, but comparable, and mediocre specificities were reported. The addition of a semiquantitative analysis through a ratio determination for ${ }^{18} \mathrm{~F}$-FDOPA [tumor/striatum ratio (T/S), tumor/normal white matter ratio $(\mathrm{T} / \mathrm{W})$, and tumor/contralateral normal brain tissue ratio $(\mathrm{T} / \mathrm{N})]$ improved specificity. A T/S ratio of 0.75 resulted in a maximum sensitivity of $100 \%$ with a specificity of $86 \%$, while a T/S ratio of 1.0 resulted in a small decrease in sensitivity (92\%) with a good specificity of $95 \%$. A 1.0 threshold in a first-line assessment or clinical suspicion of radiation necrosis was predominant, and the 0.75 threshold in inconclusive cases or with the suspicion of tumor recurrence as the most likely hypothesis (Figure 3) (95). Another study confirmed these results, with better specificities (100).

Rare false-negative glioblastoma and a few false-positive lesions have been reported, such as acute disseminated encephalomyelitis, neurosarcoidosis, demyelinating lesions, and inflammatory granulations on the resection margins, through activation of macrophages after surgery. Therefore, a weak homogeneous circumferential fixation on the resection margins should be considered with caution, as it may be caused by post-operative inflammatory changes rather than 
in association with tumor recurrence and may be closely monitored $(91,102,103)$.

${ }^{18}$ F-FDOPA as a prognostic factor: The tumor to normal tissue $(\mathrm{T} / \mathrm{N})$ ratio significantly correlated with survival in patients suspected of glioma recurrence (104). In low-grade gliomas, intensity of uptake may be an independent predictive factor of disease progression and its prognostic role was proposed (105, 106). However, unexpected and somewhat paradoxical results showed a higher capture of ${ }^{18} \mathrm{~F}$-FDOPA by IDH-mutated grade II and III gliomas compared to wildtype ones (107). Similarly, a high ${ }^{18}$ F-FDOPA uptake was predictive of a low growth rate tumor, regardless of IDH status (108).

${ }^{18} \mathrm{~F}$-FDOPA is also used to evaluate tumor response in patients with recurrent high-grade glioma treated with anti-angiogenic therapy, such as bevacizumab. The absolute MTV measured 2 and 6 weeks after the treatment initiation correlated with the tumor response (109). This predictive value based on parametric response maps showed a correlation between evolution and both PFS and OS (110).

As with ${ }^{18} \mathrm{~F}$-FDG, results should be interpreted in conjunction with MRI results and ideally using merged images if possible. In rare cases, ${ }^{18} \mathrm{~F}$-FDOPA may detect recurrences earlier than MRI. Inverse association between the ${ }^{18} \mathrm{~F}$-FDOPA uptake level and ADC and a proportional association between the ${ }^{18}$ F-FDOPA uptake level and the mitotic index have been reported $(102,111)$.

The ${ }^{18}$ F-FDOPA PET can therefore modify the management of patients with glioblastoma owing to its performances in diagnostic, therapeutic, and prognostic evaluation (89). The main drawbacks remain its cost and its availability (112).

\section{${ }^{18}$ F-FET}

To overcome the limitations for the use of ${ }^{11} \mathrm{C}$-methionine, ${ }^{18} \mathrm{~F}$-labeled amino acids have been synthesized, such as ${ }^{18} \mathrm{~F}$ FET. ${ }^{18}$ F-FET enters tumor cells through a specific amino acid transport system (LAT) and is not metabolized or incorporated into proteins.

${ }^{18} \mathrm{~F}$-FET and ${ }^{11} \mathrm{C}$-methionine showed equivalent performances in lesion detection to differentiate post-therapeutic modifications from recurrences and to confirm delineation of MTV (113). Compared with ${ }^{18}$ F-FDOPA, no significant difference was reported in visual analysis for patients either with primary or recurrent high-grade glioma. Semiquantitative analysis outlined a significant difference; however, it had no impact on the delineation of tumor volume (114).

${ }^{18} \mathrm{~F}$-FET clinical applications included guiding biopsy, tumor delineation, scheduling and monitoring treatment (surgery or radiotherapy), and distinguishing between radiation necrosis and tumor recurrence.

${ }^{18} \mathrm{~F}$-FET to target the biopsy area in patients with characteristic glioma lesions on the MRI. A lesion was considered to be suspicious of tumor when it displayed a brain/ratio $>1.6$ with ${ }^{18}$ F-FET. The addition of PET ${ }^{18}$ F-FET and MR spectroscopy to conventional MRI improved the efficiency of biopsy targeting (115).
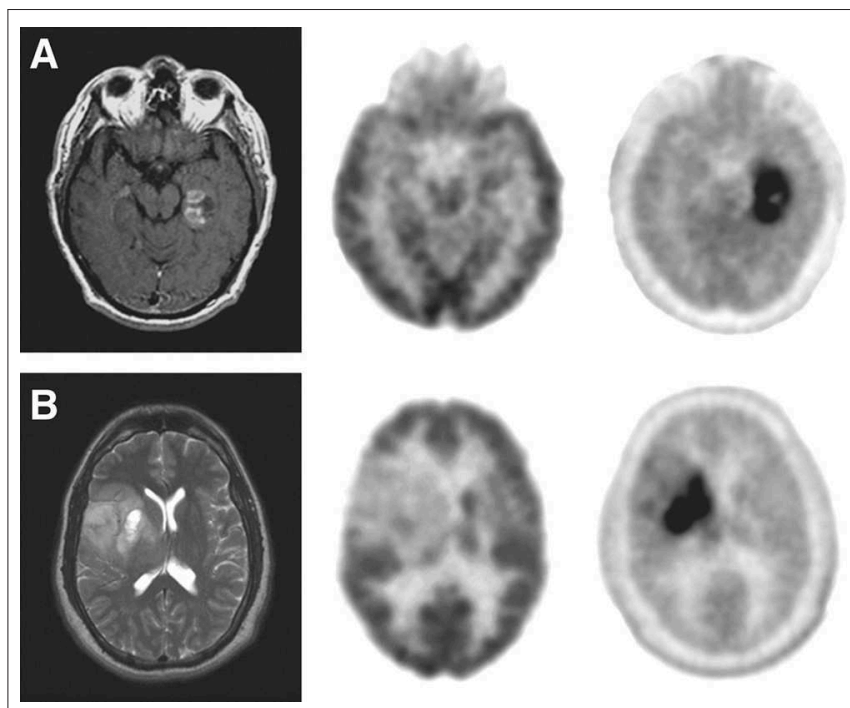

FIGURE 3 | MRI (left), ${ }^{18}$ F-FDG PET (middle), and ${ }^{18}$ F-FDOPA PET (right) of newly diagnosed tumors. (A) Glioblastoma. (B) Grade II oligodendroglioma. This research was originally published in Chen et al. (95).

${ }^{18} \mathrm{~F}-\mathrm{FET}$ results used in conjunction with MRI in tumor delineation. Tumor delineation showed larger volumes with ${ }^{18} \mathrm{~F}$ FET than relative cerebral blood volume (rCBV) on perfusionweighted MRI (116). Combined with MRI, it would better define the areas where tumors are likely to recur after radiotherapy treatment (117). It also identifies post-operative residual tumors in a more sensitive way than MRI (118). Investigating this setting through a dual time-point imaging of FET uptake at 10 and $60 \mathrm{~min}$ after radionuclide injection, some authors showed that it was less time-consuming than most dynamic data acquisition protocols but still overcomes many of the limitations of static acquisition (119).

Differentiation between low- and high-grade gliomas. One study reported no significant discrepancy between these tumors, while another retrospective study reported that a tumor-tobrain max ratio $<2.5$ could rule out a high-grade tumor with a high probability (120). Some authors have highlighted the potential contribution of dynamic acquisition. In a study based on the SUVmax lesion/background ratio, low-grade and high-grade gliomas showed statistically different uptakes and could be distinguished with a 2.58 threshold. Notwithstanding, there was a significant overlap limiting the relevance of these tools. Conversely, the dynamic acquisitions allowed a better discrimination through the time-activity curve, with an early peak at 10-20 min for high-grade gliomas, followed by a decrease, vs. a sluggish growth for low-grade gliomas $(121,122)$. Nevertheless, this dynamic acquisition takes two to three more times than a static acquisition, making it difficult to implement as routine. Early static acquisition performance at $5-15 \mathrm{~min}$ is sufficiently consistent to distinguish low- and high-grade tumors. The tumor-to-brain ratio (TBR) was more accurate on such early images than at 20-40 min, thanks to a higher ratio for high-grade tumors on the early images. However, the calculation of this early ratio remained less precise than the dynamic acquisition for this 
objective (123). Although it is a powerful tool to distinguish lowand high-grade glioma, histological analysis remains the gold standard (124).

${ }^{18} \mathrm{~F}$-FET for the differentiation between post-therapeutic modifications and relapses. ${ }^{18} \mathrm{~F}$-FET is useful to distinguish recurrence from radiation necrosis, with its low uptake after acute radiation necrosis due to $\mathrm{BBB}$ leakage. The ratio between the radiation necrosis captation and the normal cortex uptake is lower for ${ }^{18} \mathrm{~F}$-FET compared with ${ }^{18} \mathrm{~F}$-FDG and ${ }^{18} \mathrm{~F}$ fluorocholine (67).

Metabolic characteristics were explored in patients with gliomas after treatment with various therapeutic approaches and suspicion of recurrence. An intense and focal uptake suggests relapse, whereas a weak homogeneous uptake on the resection bed was rather in favor of benign post-therapeutic modifications (125).

However, these results are still being debated, and Mehrkens and collaborators adjusted these results. The examination could not replace the stereotactic biopsy (126).

The additional dynamic data mentioned above can help in differentiating low-grade from high-grade glioma tumors but also allows the discrimination of recurrences from radiation necrosis and would have a prognostic contribution. A mean tumor/brain ratio $\geq 2.0$ on static images or a time-to-peak $<45 \mathrm{~min}$ on dynamic images improves the accuracy in the discrimination of glioma recurrences from post-therapeutic changes compared to MRI. It would outperform MRI in this setting (127-129).

${ }^{18} \mathrm{~F}-\mathrm{FET}$ can also be used to differentiate an early progression after a radiochemotherapy completion from a pseudoprogression, with an uptake significantly higher in early progression than in pseudoprogression. The optimal TBR maximal threshold value for pseudoprogression was 2.3. The patients with pseudoprogression had significantly longer OS than the patients with early progression (130). The dynamic acquisition would also identify a late pseudo progression, defined as occurring beyond 3 months after completion of radiotherapy (131).

Despite its performances in differential diagnosis between the post-therapeutic modifications and recurrent changes, its specificity and image analysis remain somewhat controversial and debated. Increased amino acid tracer uptake may also occur in non-neoplastic lesions or processes (e.g., ischemic stroke, local infections related to a brain abscess, inflammatory processes such as multiple sclerosis, status epilepticus) (132-135).

Prognostic role of ${ }^{18}$ F-FET: The MTV was identified as an independent prognostic factor. A small MTV before any treatment or just after surgery before radiochemotherapy correlated with an increased OS and PFS (136-138). A TBR threshold ratio of 1.6 would correlate with OS and with disease-free survival (DFS), and would allow-after surgery and before adjuvant radiochemotherapy-the residual tumor volume to be accurately determined in order to improve the delineation. Similarly, an increased time-activity curve at baseline examination is a factor associated with a prolonged OS (137). ${ }^{18} \mathrm{~F}$-FET has a predictive role in early response to radiochemotherapy. The patients with an ${ }^{18} \mathrm{~F}$-FET uptake decrease $>10 \%$ estimated by the TBRmax on an examination performed 7-10 days after treatment discontinuation would have a longer median OS (139).

These results were relatively consistent with those of other studies (140). Nevertheless, the modification of the kinetics parameters on the dynamic acquisition during treatment had no prognostic impact (141).

${ }^{18}$ F-FET complementary role to MRI for therapeutic response assessment: Response to bevacizumab and irinotecan therapy in patients with high-grade glioma recurrence was discordant in $40 \%$ of cases. ${ }^{18}$ F-FET showed tumor progression earlier than MRI. A PET response-defined as a reduction of more than $45 \%$ of the metabolically active tumor volume, that is, with a TBR $\geq 1.6$-was observed at an early stage. This PET response significantly correlated with increased median PFS and OS. A TBR reduction $\geq 17 \%$ at follow-up allowed the discrimination of responders (PFS $\geq 6$ months) from non-responders (PFS $\leq 6$ months) with good performances. Interestingly, at baseline, kinetics characteristics, such as an early peak of capture followed by a decrease, were more often observed in nonresponder patients (142). A few years earlier, a similar study, using the same response criteria, had found consistent results. In more than one third of the cases where MRI failed to demonstrate progression according to the RANO criteria, ${ }^{18} \mathrm{~F}-$ FET PET detected progression. Survival was significantly higher in responders than in non-responders (143). This approach could be cost-effective while avoiding continuation of ineffective treatment with associated side effects and costs. These medicoeconomic aspects should also be considered in the area of personalized medicine, where costs associated with new treatments, such as targeted treatments and immunotherapy, are soaring (144).

${ }^{18}$ F-FET may contribute to improving management of patients pursuing a tumor-treating field (TTF) therapy. This innovative treatment consists of using transducers to deliver an electric wave, transformed into electromagnetic energy to the scalp. The low-intensity and intermediate-frequency waves $(200 \mathrm{kHz})$ generated in the brain are toxic to cells. It prevents neoplastic cell division and causes neoplastic cell death, with no significant effect on normal quiescent cells. This adjuvant therapy with temozolomide improves PFS and OS in patients who have completed initial radiochemotherapy treatment. The ${ }^{18}$ F-FET TBRmax and TBRmean ratios have been proposed to discriminate relapses from post-therapeutic changes (145).

The recent advances are no longer limited to studying the standard static and dynamic parameters of ${ }^{18}$ F-FET. Radiomics parameters based on textural features can be associated with reflect tumor heterogeneity, with good performances in the subgrading of high-grade gliomas (grade III vs. grade IV); they have a predictive role for tumor progression and correlate with OS (146). Kebir and collaborators highlighted their role in the detection of pseudoprogression (147). In addition, the combination of conventional static and dynamic criteria with radiomic parameters allows a non-invasive prediction of IDH status with good performances (148). The current drawbacks of such parameters are that textural feature analysis is influenced by image quality, especially by the spatial 
resolution, and post-processing of image data is complex and time-consuming.

According to Galldiks and collaborators, ${ }^{18} \mathrm{~F}$-FET should be preferred to other radiolabeled amino acids because of its logistical advantage, thanks to its ${ }^{18} \mathrm{~F}$ radiolabel, the absence of striatum uptake, and the accurate discrimination between highand low-grade glioma with kinetics parameters from dynamic acquisition (149). However, it is not available in all countries.

\section{RADIOLABELED NUCLEOSIDE ANALOG: ${ }^{18}$ F-FLT}

${ }^{18}$ F-FLT is a thymidine analog that is phosphorylated by thymidine kinase-1, an enzyme whose activity is increased in tumor cells, and that operates during the DNA synthesis. However, this substrate is not incorporated into DNA (112). ${ }^{18} \mathrm{~F}$ FLT capture requires the rupture of the BBB and reflects cell proliferation-more precisely, the fraction of tumor cells in the S phase (150).

The use of ${ }^{18}$ F-FLT in grading gliomas: Glioblastomas display a higher uptake ratio than astrocytomas $(p<0.01)(151) .{ }^{18}$ F-FLT uptake significantly differs according to the lesion/background ratio in high- and low-grade tumors from different brain benign and neoplastic lesions. The proliferation index (Ki-67) correlates with the ${ }^{18}$ F-FLT fixation in gliomas. However, ${ }^{18}$ F-FLT failed to distinguish non-tumor lesions from low-grade tumors (152). ${ }^{18}$ F-FLT use was more efficient than ${ }^{18}$ F-FDG in detecting recurrences of high-grade tumors, predicting tumor progression and survival in the follow-up of patients with low- and highgrade gliomas, and ${ }^{18} \mathrm{~F}-\mathrm{FLT}$ results correlated with the Ki-67 proliferation index (153).

Role of ${ }^{18} \mathrm{~F}$-FLT in discriminating radiation necrosis from tumor recurrence: Enslow and collaborators have demonstrated the potential use of ${ }^{18} \mathrm{~F}$-FLT in patients with suspected recurrence of treated gliomas of grade $\geq$ II: visual and quantitative analysis allows distinction between radiation necrosis from tumor recurrence. However, ${ }^{18} \mathrm{~F}$-FLT failed to prove its superiority in this setting compared to ${ }^{18}$ F-FDG (154).

The prognostic role of ${ }^{18} \mathrm{~F}$-FLT. The proliferative volume is a prognostic factor before treatment. The proliferative volume assessed through the signal-to-background ratio (SBR) for an adaptive threshold delineation (PVSBR) segmentation method in patients followed up for high-grade gliomas was significantly associated with OS compared with SUVmax or with the proliferative volume estimated according to other segmentation methods (155).

The predictive role of ${ }^{18} \mathrm{~F}$-FLT in assessing response to treatment: Metabolic changes at 2 and 6 weeks after treatment initiation significantly correlated with PFS and OS in patients followed for glioma after bevacizumab administration, the metabolic response being defined as a decrease equal to or greater than $25 \%$ in tumor ${ }^{18} \mathrm{~F}$-FLT standardized uptake values from baseline. The subsequent median OS was 3.3 times longer in responders than in non-responders. ${ }^{18}$ F-FLT PET was more predictive than MRI for early response to treatment (156). These results confirm prior results in recurrent malignant gliomas treated with bevacizumab and irinotecan. Whether earlier imaging at 1-2 weeks could be a predictive factor as accurate as later imaging at 6 weeks remains to be confirmed (157). Dynamic acquisitions have shown their interests in predicting survival in patients followed for recurrent glioma treated with bevacizumab and irinotecan. The prognostic value of kinetic parameters of ${ }^{18}$ F-FLT, estimated 2 weeks after the beginning of the treatment, was more relevant than that of ${ }^{18}$ F-FDOPA (158). The parametric response maps modifications correlated with PFS in patients treated with bevacizumab. However, the ${ }^{18}$ F-FLT was not associated with OS (110).

\section{HYPOXIA IMAGING: ${ }^{18}$ F-FMISO AND ${ }^{18}$ F-FAZA}

${ }^{18} \mathrm{~F}$-FMISO is a hypoxia tracer. It is a nitro-imidazole derivative whose metabolites are blocked in hypoxic cells. It is a positive tracer of hypoxia; its uptake is inversely proportional to the partial pressure in oxygen. It diffuses into the cells, is reduced in the case of hypoxia, and then remains trapped in the cells. Its role could be crucial because hypoxia is related to tumor aggressiveness and resistance to radiation treatment. Its uptake does not depend on the strength of the tumor perfusion or on the BBB permeability (159). Its uptake is significantly correlated with the Ki-67 proliferation index (160).

Its main drawback is its lipophilicity, which generates a high background activity and requires both early and delayed acquisitions (112).

${ }^{18} \mathrm{~F}$-FMiso is complementary to MRI. ${ }^{18} \mathrm{~F}$-FMISO uptake straddles the peripheral area of the anomalies found in $\mathrm{T} 1$ gadolinium, supporting the principle that local hypoxia leads to the production of angiogenic factors, themselves leading to the creation of neovasculature (161).

Use of ${ }^{18} \mathrm{~F}$-FMISO to discriminate glioblastomas from other gliomas: An intense and significant fixation relative to surrounding cerebral background has been reported in patients with glioblastomas compared with those with other gliomas. The sensitivity and specificity in glioblastoma detection were higher using ${ }^{18}$ F-FMISO than using ${ }^{18}$ F-FDG. Similarly, the lesion/cerebellum ratio was higher in patients followed for glioblastoma than in non-glioblastoma patients, without overlap between these two groups (162).

Hypoxia measured on ${ }^{18} \mathrm{~F}-\mathrm{FMISO}$ PET as prognostic factor: An increase in SUVpeak before treatment with radiochemotherapy was associated with a shorter OS in patients followed for glioblastoma (163). Similarly, the intensity and volume of tumor hypoxia in glioblastomas are significantly correlated with time to progression and survival $(162,164,165)$.

${ }^{18} \mathrm{~F}$ - Fluoroazomycinarabinofuranoside $\left({ }^{18} \mathrm{~F}\right.$-FAZA), another tracer of hypoxia, displays a better signal-to-noise ratio due to less lipophilic properties and greater clearance. It may help identify small hypoxic tumor areas confined in hypometabolic necrotic areas, as revealed with ${ }^{18} \mathrm{~F}$-FDG. These data would be of potential interest for radiotherapy planning (166).

Hypoxia is a poor prognostic factor, causing resistance to radiation therapy, leading to poorer local control. Using these 
TABLE 1 | Advantages and drawbacks of main radiotracers used in gliomas investigation in functional nuclear imaging.

\begin{tabular}{|c|c|c|c|}
\hline & Physiopathology & Advantages & Drawbacks \\
\hline $18 F-F D G$ & $\begin{array}{l}\text { Carbohydrate } \\
\text { metabolism }\end{array}$ & $\begin{array}{l}\text { - Availability } \\
\text { - Help in guiding biopsy } \\
\text { - Prognostic role } \\
\text { - Predictive role }\end{array}$ & $\begin{array}{l}\text { - Physiological brain fixation (false negative) } \\
\text { - Lack of specificity (false positive) } \\
\text { - No differentiation between low-and high-grade lesion } \\
\text { - Disappointing in recurrence from radiation } \\
\text { necrosis differentiating } \\
\text { - Disappointing in radiotherapy planning }\end{array}$ \\
\hline 11C-methionine & Amino acid transport & $\begin{array}{l}\text { - Grading gliomas } \\
\text { - Help in guiding stereotactic biopsy } \\
\text { - Radiotherapy planning } \\
\text { - - Predictive role }\end{array}$ & $\begin{array}{l}\text { - Limited use to on-site cyclotron } \\
\text { - Controversial and results in differentiation between } \\
\text { radiation necrosis and tumor recurrence }\end{array}$ \\
\hline 18F-FDOPA & Amino acid transport & $\begin{array}{l}\text { - Logistical advantage thanks to its }{ }^{18} \mathrm{~F} \text { radiolabel } \\
\text { - Early acquisition } \\
\text { - Grading gliomas } \\
\text { - Guiding biopsy } \\
\text { - Radiotherapy planning } \\
\text { - Recurrence from radiation necrosis differentiation } \\
\text { - Prognostic role } \\
\text { - Predictive role }\end{array}$ & $\begin{array}{l}\text { - Disappointing in radiotherapy planning } \\
\text { - Availability compared to radiolabeled -PSMA }\end{array}$ \\
\hline 18F-FET & Amino acid transport & $\begin{array}{l}\text { - Logistical advantage thanks to its }{ }^{18} \mathrm{~F} \text { radiolabel } \\
\text { - No striatum uptake } \\
\text { - Dynamic acquisition } \\
\text { - Grading gliomas } \\
\text { - Guiding biopsy } \\
\text { - Radiotherapy planning } \\
\text { - Recurrence from radiation necrosis differentiation } \\
\text { - Prognostic role } \\
\text { - - Predictive role }\end{array}$ & - Availability \\
\hline 18F-FLT & DNA synthesis & $\begin{array}{l}\text { - Grading gliomas } \\
\text { - Prognostic role } \\
\text { - Predictive role }\end{array}$ & $\begin{array}{l}\text { - No distinction between non-tumor lesions and low- } \\
\text { grade tumors } \\
\text { - Compared to } 18 \text { F-FDG no superiority in discriminating } \\
\text { radiation necrosis from tumor recurrence }\end{array}$ \\
\hline
\end{tabular}

hypoxia tracers, identification of these intratumor hypoxic areas would make it possible to increase radiation doses to the whole tumor or to specifically target the hypoxic zones (167). However, it should be noted that there is temporal and spatial variability of small hypoxic and necrotic zones, which could compound the role and contribution of hypoxia imaging in tumor exploration (168).

\section{NEW TRACERS UNDER DEVELOPMENT IN THIS SETTING}

Each aforementioned tracer has shortcomings (Table 1), which hamper PET imaging in playing a major role in glioblastoma management (169). The unexpected role of the transmembrane glycoprotein prostate-specific membrane antigen (PMSA) encoded by the FOHL1 gene, and overexpressed in prostate adenocarcinomas, may overcome some drawbacks. Radiolabeling of PMSA with the positron emitter gallium 68 is readily available, thanks to a $68 \mathrm{Ge} / 68 \mathrm{Ga}$ on-site generator. It can also be radiolabeled with ${ }^{18} \mathrm{~F}$, such as ${ }^{18} \mathrm{~F}$-DCFPyL or ${ }^{18}$ F-PSMA-1007, but synthesis with cyclotron sites is not achievable (170). PMSA can be targeted with small molecular ligands, such as 68Ga-(HBED-CC), also named 68Ga-PSMA-11. The key role of this PMSA in prostate cancer care tends to replace ${ }^{18} \mathrm{~F}$-fluorocholine PET/CT and bone scan to become a standard (171-175). 


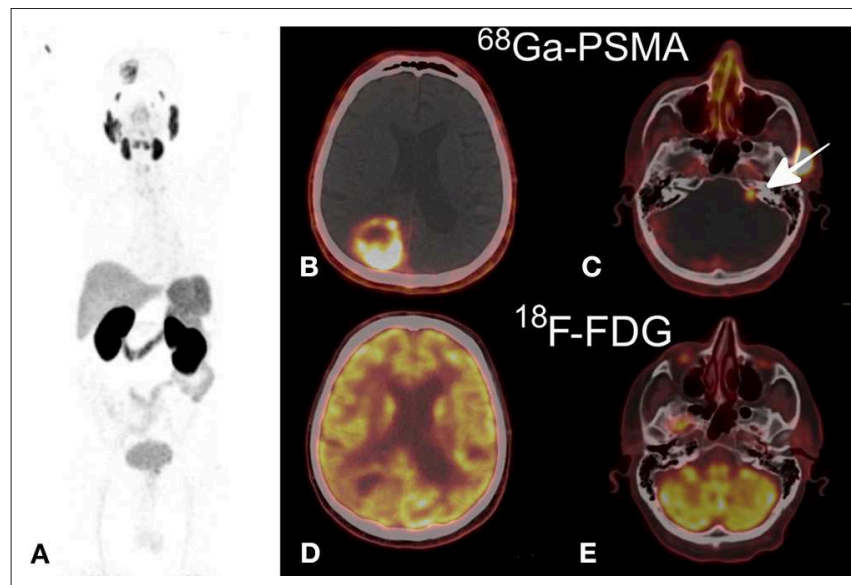

FIGURE 4 | (A) Maximum intensity projection ${ }^{68}$ Ga-PSMA (MIP), (B,C) ${ }^{68}$ Ga-PSMA axial PET/CT fusion demonstrating a non-homogeneous uptake in the right parietal mass (B) and a lower uptake in the left auditory neuroma (C), (D,E) ${ }^{18}$ F-FDG axial PET/CT fusion showing an increased uptake comparable to that in the gray matter in the parietal tumor (D) and no uptake in the neuroma (E). This research was originally published in Kunikowska et al. (186).

PSMA is not specific to prostate cancer. PSMA is highly expressed in many other cells, such as renal proximal tubular epithelium and duodenum columnar epithelium. PMSA is also expressed in the endothelium of tumor-associated neovasculature but never in malignant tumor cells themselves nor in normal vessels (176-178).

This was confirmed in a recent study, which demontrates that two thirds of glioblastoma neovasculatures express PSMA with a high and moderate intensity in most cases, with no correlation between PSMA expression and endothelial proliferation (179).

Glioblastoma multiformes, among the most vascularized tumors, also express PSMA, which could represent a new target of choice. Compared to glioblastomas, grade II and III gliomas have a weaker expression, with predominant expression located not on vessels, but on astrocytes. Normal cerebral parenchyma expresses little or no PSMA either in brain cells or vessels (180, 181). The PSMA may be implicated in angiogenesis through its participation in the destruction of the extracellular matrix during the invasion by neovessels and modulation of the integrin transduction signal in a complex way (182). Its folate activity may facilitate angiogenesis and vasculogenesis by increasing local folic acid availability.

However, Gordon and collaborators reported a PSMA overexpression in some non-neoplastic neovasculatures involved in repair and regeneration mechanisms, such as granulation tissues and scars (183).

The visualization of glioblastoma with ${ }^{68} \mathrm{Ga}$-PSMA has previously been reported and is a potential false positive and can be the source of pitfalls $(184,185)$. A few case reports have shown glioblastomas with PSMA radiolabeled with either $68 \mathrm{Ga}$ or $18 \mathrm{~F}$, the intense uptake being consistent with contrast-enhancing tumor on MRI (Figure 4) (186-188).

Sasikumar and collaborators compared ${ }^{68} \mathrm{Ga}$-PSMA PET/CT and ${ }^{18} \mathrm{~F}-\mathrm{FDG}$ PET/CT in a series of 10 patients followed for various brain tumors, including five patients suspected of glioblastoma recurrence, with the aim to characterize the lesions or to make the differential diagnosis between radiation necrosis and recurrence. The authors highlighted the superiority of ${ }^{68} \mathrm{Ga}$ PSMA over ${ }^{18}$ F-FDG, owing to an advantageous target-tobackground ratio. The four glioblastoma relapses were correctly and easily identified (189).

The same team later published a series of 15 patients followed for gliomas, including 10 glioblastomas, imaged with ${ }^{68} \mathrm{Ga}-\mathrm{PSMA}$ PET/CT. The authors confirmed previous results in patients for post-treatment recurrence assessment. The examination also identified the residual disease immediately after surgery more clearly than MRI.

However, a case of cerebral radionecrosis demonstrating ${ }^{18} \mathrm{~F}$ DCFPyL uptake has been published, highlighting this entity as a possible pitfall while interpreting this examination (190).

Characterizing high- and low-grade glioma in treatmentnaive patients, Verma et al. demonstrated higher ${ }^{68} \mathrm{Ga}$-PSMA11 uptake and tumor-to-background ratio in high-grade glioma than in low-grade ones. PSMA SUVmax and MIB-1 both correlated with the tumor grade (191).

Further evidence from robust studies are needed to define the precise role of this imaging in the evaluation of gliomas (evaluation of recurrences, radiotherapy planning, and immediate post-surgery restaging, among others) (192).

Whether it could be used in peptide therapy with $\alpha$ or $\beta$ emitters is still being discussed. The effectiveness of such a treatment could be reduced by the distance to be covered by the $\beta$ - to reach the tumor cells, the PSMA being expressed by the neovessels, and not by the glial cells themselves. The absence of tracer internalization in glial cells hinders its theranostic use. The radiation on the neovessels and its potential tumoricidal efficiency can only be speculated. Dosimetric studies are required $(186,193)$.

Many other tracers have been proposed and studied (57).

Matsuda and collaborators successfully imaged PSMA expression in three patients followed for recurrent high-grade gliomas and brain metastases using ${ }^{89} \mathrm{Zr}$-Df-IAB2M anti-PSMA minibody and outlined a trend for the binding intensity of this tracer to correlate with PSMA expression level in tumor vessels. This tracer may play a role in distinguishing between post-therapeutic recurrence and radiation necrosis, as well as in predicting efficacy and evaluating tumor response under bevacizumab (194).

Somatostatin receptors, especially SSTR2 subtype, are overexpressed in neuroendocrine tumors, allowing their visualization with ${ }^{68} \mathrm{Ga}$-radiolabeled somatostatin analogs, such as ${ }^{68} \mathrm{Ga}$-DOTATATE. These receptors are also overexpressed in activated macrophages, leading to false-positive inflammatory lesions. Some authors studied the potential use of ${ }^{68} \mathrm{Ga}$ DOTATATE to assess glioblastomas that belong to the wide group of tumor-associated macrophages. They failed to prove the interest of ${ }^{68} \mathrm{Ga}$-DOTATATE because of a weak SSTR2A expression on the cell surface of infiltrating macrophages and on tumor cells (195).

Other investigations explored the interest of radioguided surgery with $\beta$ - isotopes in high-grade glioma. The aim of this 
technique, based on the same rules as sentinel node mapping, is to help the surgeon during resection to evaluate the extent of the resection and to maximize the resection margins while minimizing the peripheral parenchyma resection surrounding the lesion. A tumor-specific tracer, in this case ${ }^{90} \mathrm{Y}$-DOTATOC, was injected before surgery. Its radiolabeling with a $\beta$ - emitting isotope makes it possible to get rid of the background noise obtained with a gamma isotope. Specific detection probes were used to collect information in real time. Although it was less interesting than in meningioma because of a lower uptake, the tumor-to-non-tumor ratio was strong enough to support the use of this technique in high-grade gliomas (196). The place of this tracer in glioblastoma evaluation remains uncertain, with probably less potential impact than for meningiomas, due to the low expression of these receptors by tumor cells.

${ }^{11} \mathrm{C}$-alpha-methyltryptophan (AMT) could be an alternative to ${ }^{11} \mathrm{C}$-methionine, but this does not avoid the need for onsite cyclotron (57). It has demonstrated its value in both discrimination between radiation necrosis and recurrence and in the detection of post-therapeutic recurrences. This tracer is accumulated in cells of gliomas and metabolized by the kynurenine pathway, without being incorporated into proteins. Kinetic analyses on dynamic acquisitions allowed precise discrimination between recurrence and radiation necrosis. The tracer also has a prognostic role, the intensity of fixation being correlated with OS $(197,198)$.

${ }^{18} \mathrm{~F}$-fluciclovin, also called anti-[ $\left.{ }^{18} \mathrm{~F}\right] \mathrm{FACBC}$, a new ${ }^{18} \mathrm{~F}$ labeled amino acid, was tested in patients followed for gliomas in a phase II study. The authors concluded that this radiotracer was safe, and that it was able to delineate the gliomatous invasion in cases where it could go unnoticed on the MRI (199).

Another amino acid pathway is glutamine, which together with glucose, is one of the two nutrients necessary for cell proliferation and survival. A radiolabeled ${ }^{18} \mathrm{~F}$ glutamine analog $4-{ }^{18} \mathrm{~F}$-(2S,4R)-fluoroglutamine or ${ }^{18} \mathrm{~F}-\mathrm{FGln}$ demonstrated a very high lesion/background ratio, no uptake in neuroinflammatory lesions, an absence of leakage through the permeable $\mathrm{BBB}$, and a correlation between the decrease in its fixation and tumor shrinkage. It succeeded in displaying a suitable lesion/background ratio in a patient followed for a glioblastoma (200).

${ }^{11} \mathrm{C}-(\mathrm{R}) \mathrm{PK} 11195$, selectively binds to a mitochondrial translocator protein (TSPO), which is upregulated in highgrade astrocytomas but not in healthy brain parenchyma. This tracer has theranostic potential by being a potential target for targeted treatments or for the passage of nanoparticles. TSPO was expressed predominantly by neoplastic cells, and its ligand, ${ }^{11} \mathrm{C}-(\mathrm{R}) \mathrm{PK} 11195$, binds more strongly in high-grade gliomas than in low-grade gliomas. However, its ${ }^{11} \mathrm{C}$ radiolabeling could limit its use (201). Other TSP- ${ }^{18} \mathrm{~F}$ radiolabeled ligands, the ${ }^{18} \mathrm{~F}-\mathrm{DPA}-714$, with higher binding potential achieved visualization of gliomas in preclinical studies (202). Another ${ }^{18} \mathrm{~F}$-labeled ligand investigated in patients followed for pre- or post-treatment glioblastoma, the ${ }^{18}$ F-GE-180, displayed a significant tumor-to-background contrast. The PET volume based on tracer uptake was larger than the volume based on MRI-enhanced tumor, thanks to tumor areas capturing the ${ }^{18} \mathrm{~F}-\mathrm{GE}-180$ even outside the areas enhanced on MRI. Broader prospective studies with histological comparison are needed to eliminate uptake related to inflammation (203).

Recent studies on ${ }^{68} \mathrm{Ga}$-radiolabeled bombesin analogs in glioma exploration are emerging. NOTA-Aca-BBN (7-14) (or ${ }^{68} \mathrm{Ga}-\mathrm{BBN}$ ) tested in volunteer patients and patients followed for gliomas had no side effects and an advantageous dosimetry. The binding intensity correlated with the expression level of gastrinreleasing peptide receptor. The authors stressed the potential theranostic role of this tracer $(204,205)$.

${ }^{62} \mathrm{Cu}$-diacetyl-bis (N4-methylthiosemicarbazone), more simply named ${ }^{62} \mathrm{Cu}$-ATSM, could replace ${ }^{18} \mathrm{~F}$-FMISO in the imaging of hypoxic metabolism in gliomas. The binding of ${ }^{62} \mathrm{Cu}$-ATSM was significantly higher in glioblastoma than in grade III glioma. Uptake correlated with the expression of the HIF-1 marker (206).

Acetate is a potential source of energy, which can be radiolabeled with ${ }^{11} \mathrm{C}$. In a study involving patients followed for gliomas, including glioblastoma, this tracer compared to ${ }^{18} \mathrm{~F}$-methionine and ${ }^{18} \mathrm{~F}-\mathrm{FDG}$ had

TABLE 2 | Main radiotracers performances in gliomas recurrence distinction and in discriminating recurrence from post-therapeutic modifications.

\begin{tabular}{|c|c|c|c|c|c|}
\hline & Sensitivity \% & Specificity \% & $\begin{array}{c}\text { Positive predictive } \\
\text { value } \%\end{array}$ & $\begin{array}{c}\text { Negative } \\
\text { predictive value } \%\end{array}$ & Accuracy $\%$ \\
\hline 18F-FDG & $\begin{array}{c}43-100 \\
(29,42,68,77,78,100,152)\end{array}$ & $\begin{array}{c}40-100 \\
(29,42,68,77,78,100,152)\end{array}$ & $\begin{array}{c}80-00 \\
(100,152)\end{array}$ & $\begin{array}{c}20-38.9 \\
(100,152)\end{array}$ & $\begin{array}{l}60.7 \\
(100)\end{array}$ \\
\hline $\begin{array}{l}\text { 11C-choline and } \\
\text { 18F-Fcholine }\end{array}$ & $\begin{array}{c}73.5-92.3 \% \\
(68,77)\end{array}$ & $\begin{array}{l}87.5 \% \\
(68,77)\end{array}$ & NA & NA & NA \\
\hline 11C-methionine & $\begin{array}{l}75-91.2 \% \\
(77,78)\end{array}$ & $\begin{array}{c}87.5-100 \\
(77,78)\end{array}$ & NA & NA & NA \\
\hline 18F-FDOPA & $\begin{array}{c}84-100 \\
(95,100,101)\end{array}$ & $\begin{array}{c}62.1-100 \\
(95,100,101)\end{array}$ & $\begin{array}{c}89.6-100 \\
(95,100,101)\end{array}$ & $\begin{array}{c}63.4-100 \\
(95,100,101)\end{array}$ & $\begin{array}{c}78-97 \\
(95,100,101)\end{array}$ \\
\hline 18F-FET & $\begin{array}{c}84-100 \\
(126,128-130)\end{array}$ & $\begin{array}{c}86-100 \\
(126,128-130)\end{array}$ & $\begin{array}{c}84-100 \\
(125,128)\end{array}$ & NA & $\begin{array}{c}85-96 \\
(128-130)\end{array}$ \\
\hline 18F-FLT & $\begin{array}{l}82.1 \\
(152)\end{array}$ & $\begin{array}{c}50 \\
(152)\end{array}$ & $\begin{array}{l}73.3 \\
(152)\end{array}$ & $\begin{array}{l}26.7 \\
(152)\end{array}$ & NA \\
\hline
\end{tabular}


a sensitivity of $90 \%$ in glioma detection (vs. 100 and $40 \%$, respectively). Its uptake was significantly higher in high-grade gliomas than in those of low-grade (207). These results were further confirmed by another study, showing a significantly higher uptake and tumor/cortex (T/C) ratio for high-grade gliomas than for low-grade gliomas (208).

The ${ }^{18}$ F-labeled-2-(5-fluoro-pentyl)-2-methyl-malonic acid $\left(\left[{ }^{18} \mathrm{~F}\right] \mathrm{ML} 10\right)$ is a useful tracer for apoptosis that characteristically highlights cells that have acquired permanent membrane depolarization. This tracer used in a small series of patients followed for glioblastoma failed to prove a correlation between changes in tracer uptake and time to progression. The authors hypothesized that this failure was secondary to a variable rate of cell growth and death between the different lesions (209).

Some authors explored integrin-specific radiopharmaceutical $\alpha_{\mathrm{v}} \beta_{3},{ }^{68} \mathrm{Ga}-\mathrm{BNOTA}-\mathrm{PRGD} 2$ ( ${ }^{68} \mathrm{Ga}$-PRGD2), in glioma. This tracer accumulated in integrin-rich lesions (overexpressed especially in neovessels and glioma cells) and in choroid plexuses, but not in the rest of the healthy cerebral parenchyma in a small series of patients with high-grade gliomas. SUVmax and TBRmax were both significantly correlated with tumor grade, and ${ }^{68} \mathrm{Ga}-\mathrm{PRGD} 2$ was greater than ${ }^{18} \mathrm{~F}-\mathrm{FDG}$ in distinguishing low-grade glioma from high-grade glioma, even allowing discrimination between grade III glioma and grade IV glioma (210). These results confirm prior results in patients with glioblastomas, with another tracer radiolabeled with ${ }^{18} \mathrm{~F}$, the Arg-Gly-Asp peptide ( ${ }^{18} \mathrm{~F}$-galacto-RGD) (211).

${ }^{18} \mathrm{~F}$-AlF-NOTA-PRGD2 ( $\left.{ }^{18} \mathrm{~F}-\mathrm{RGD}\right)$, another integrin-specific tracer, may play a predictive role in assessing early response to chemotherapy (212).

However, these tracers are only under experimentation, further larger studies are needed, including prospective clinical trials comparing these innovative tracers to the current more standard radiolabeled amino acids.

Finally, the development of PET-MRI opens up the possibility to study the various PET and MRI parameters in a single investigation and in a relatively short time. The problem of the attenuation correction is not perfectly solved and the high cost of such equipment is nevertheless a major constraint on their uptake (213).

\section{REFERENCES}

1. Louis DN, Perry A, Reifenberger G, von Deimling A, Figarella-Branger D, Cavenee WK, et al. The 2016 World Health Organization Classification of Tumors of the Central Nervous System: a summary. Acta Neuropathol. (2016) 131:803-20. doi: 10.1007/s00401-016-1545-1

2. Adamson C, Kanu OO, Mehta AI, Di C, Lin N, Mattox AK, et al. Glioblastoma multiforme: a review of where we have been and where we are going. Expert Opin Investig Drugs. (2009) 18:1061-83. doi: 10.1517/13543780903052764

3. Stupp R, Hegi ME, Mason WP, van den Bent MJ, Taphoorn MJB, Janzer RC, et al. Effects of radiotherapy with concomitant and adjuvant temozolomide versus radiotherapy alone on survival in glioblastoma in a randomised phase

\section{SYNTHESIS AND OUTLOOK}

Due to the emergence of new different therapies in the management of glioblastoma and poor prognosis of this disease, it is crucial to have reliable evaluation imaging.

PET imaging is an additional tool that should be used in conjunction with MRI, thanks to these numerous tracers and their multiple contributions. Despite an insufficient role in the differentiation between tumor recurrence and radiation injury, ${ }^{18}$ F-FDG still plays an important prognostic role. Regarding the use of radiolabeled amino acids, the spread of ${ }^{11} \mathrm{C}$-methionine is hampered by the need for on-site cyclotron. The ${ }^{18} \mathrm{~F}-\mathrm{FET}$ and ${ }^{18}$ F-FDOPA are more easily accessible, thanks to their fluorine18 radiolabeling, with excellent properties at all grades of the pathology. They display reliable performances in distinguishing post-radiation-related modifications and tumor recurrence (Table 2) and improved early assessment of tumor response during antiangiogenic treatment. These tools are currently recommended in equivocal situations only. The developement of ${ }^{68} \mathrm{Ga}$-PSMA seems very promising in the distinction between radiation injury and relapse. Its synthesis is straightforward to implement, and its availability makes it a potentially more accessible and less expensive tracer. Early distinction of tumor recurrence from a post-radiation complication at a lower cost is of paramount importance because of the soaring costs of targeted treatments. Considering the poor prognosis of this pathology, no time should be lost due to indecision. Another potential advantage of PSMA is its possible theranostic use. However, the precise place of this new tracer is yet to be defined, and powerful prospective clinical trials are needed.

\section{AUTHOR CONTRIBUTIONS}

AM and DK: conception, design, and writing all sections of the manuscript. TM, OF, and DF: provided the literature and writing sections of the manuscript.

\section{ACKNOWLEDGMENTS}

The authors would like to thank Marie Lise Coulomb for her work as a graphic designer, and Sophie Darnis for assistance in proofreading.

III study: 5-year analysis of the EORTC-NCIC trial. Lancet Oncol. (2009) 10:459-66. doi: 10.1016/S1470-2045(09)70025-7

4. Cohen A, Holmen S, Colman H. IDH1 and IDH2 Mutations in Gliomas. Curr Neurol Neurosci Rep. (2013) 13:345. doi: 10.1007/s11910-013-0345-4

5. Sanson M. Marqueurs tumoraux des gliomes. J Neuroradiol. (2016) 43:74-5. doi: 10.1016/j.neurad.2016.01.032

6. Schwartzbaum JA, Fisher JL, Aldape KD, Wrensch M. Epidemiology and molecular pathology of glioma. Nat Clin Pract Neurol. (2006) 2:494-503. doi: 10.1038/ncpneuro0289

7. Wen PY, Kesari S. Malignant gliomas in adults. N Engl J Med. (2008) 359:492-507. doi: 10.1056/NEJMra0708126

8. Weller M, van den Bent M, Hopkins K, Tonn JC, Stupp R, Falini $\mathrm{A}$, et al. EANO guideline for the diagnosis and treatment of 
anaplastic gliomas and glioblastoma. Lancet Oncol. (2014) 15:e395-403. doi: 10.1016/S1470-2045(14)70011-7

9. Reni M, Mazza E, Zanon S, Gatta G, Vecht CJ. Central nervous system gliomas. Crit Rev Oncol Hematol. (2017) 113:213-34. doi: 10.1016/j.critrevonc.2017.03.021

10. Marko NF, Weil RJ, Schroeder JL, Lang FF, Suki D, Sawaya RE. Extent of Resection of glioblastoma revisited: personalized survival modeling facilitates more accurate survival prediction and supports a maximumsafe-resection approach to Surgery. J Clin Oncol. (2014) 32:774-82. doi: 10.1200/JCO.2013.51.8886

11. Lacroix M, Toms SA. Maximum Safe resection of glioblastoma Multiforme. J Clin Oncol. (2014) 32:727-8. doi: 10.1200/JCO.2013.53.2788

12. Li YM, Suki D, Hess K, Sawaya R. The influence of maximum safe resection of glioblastoma on survival in 1229 patients: can we do better than gross-total resection? J Neurosurg. (2016) 124:977-88. doi: 10.3171/2015.5.JNS142087

13. Laperriere N, Zuraw L, Cairncross G. Radiotherapy for newly diagnosed malignant glioma in adults: a systematic review. Radiother Oncol. (2002) 64:259-73. doi: 10.1016/S0167-8140(02) 00078-6

14. Athanassiou H, Synodinou M, Maragoudakis E, Paraskevaidis M, Verigos C, Misailidou D, et al. Randomized phase II study of temozolomide and radiotherapy compared with radiotherapy alone in newly diagnosed glioblastoma Multiforme. J Clin Oncol. (2005) 23:2372-7. doi: $10.1200 / J C O .2005 .00 .331$

15. Stupp R, Mason WP, van den Bent MJ, Weller M, Fisher B, Taphoorn MJB, et al. Radiotherapy plus concomitant and adjuvant temozolomide for glioblastoma. N Engl J Med. (2005) 352:987-96. doi: 10.1056/NEJMoa043330

16. Hegi ME, Diserens A-C, Gorlia T, Hamou M-F, de Tribolet N, Weller M, et al. MGMT gene silencing and benefit from temozolomide in glioblastoma. N Engl J Med. (2005) 352:997-1003. doi: 10.1056/NEJMoa043331

17. Chinot OL, Wick W, Mason W, Henriksson R, Saran F, Nishikawa $\mathrm{R}$, et al. Bevacizumab plus radiotherapy-temozolomide for newly diagnosed glioblastoma. $N$ Engl J Med. (2014) 370:709-22. doi: 10.1056/NEJMoa1308345

18. Gilbert MR, Dignam JJ, Armstrong TS, Wefel JS, Blumenthal DT, Vogelbaum MA, et al. A randomized trial of bevacizumab for newly diagnosed glioblastoma. N Engl J Med. (2014) 370:699-708. doi: 10.1056/NEJMoa1308573

19. Brandsma D, Stalpers L, Taal W, Sminia P, van den Bent MJ. Clinical features, mechanisms, and management of pseudoprogression in malignant gliomas. Lancet Oncol. (2008) 9:453-61. doi: 10.1016/S1470-2045(08) 70125-6

20. Stuplich M, Hadizadeh DR, Kuchelmeister K, Scorzin J, Filss C, Langen $\mathrm{K}-\mathrm{J}$, et al. Late and prolonged pseudoprogression in glioblastoma after treatment with lomustine and temozolomide. I Clin Oncol Off J Am Soc Clin Oncol. (2012) 30:e180-3. doi: 10.1200/JCO.2011. 40.9565

21. Langleben DD, Segall GM. PET in differentiation of recurrent brain tumor from radiation Injury*. J Nucl Med. (2000) 41:1861-7.

22. Kumar AJ, Leeds NE, Fuller GN, Van Tassel P, Maor MH, Sawaya RE, et al. Malignant gliomas: MR imaging spectrum of radiation therapy- and chemotherapy-induced necrosis of the brain after treatment. Radiology. (2000) 217:377-84. doi: 10.1148/radiology.217.2.r00nv36377

23. Delgado-López PD, Riñones-Mena E, Corrales-García EM. Treatmentrelated changes in glioblastoma: a review on the controversies in response assessment criteria and the concepts of true progression, pseudoprogression, pseudoresponse and radionecrosis. Clin Transl Oncol Off Publ Fed Span Oncol Soc Natl Cancer Inst Mex. (2018) 20:939-53. doi: 10.1007/s12094-017$1816-\mathrm{x}$

24. Ellingson BM, Chung C, Pope WB, Boxerman JL, Kaufmann TJ. Pseudoprogression, radionecrosis, inflammation or true tumor progression? Challenges associated with glioblastoma response assessment in an evolving therapeutic landscape. J Neurooncol. (2017) 134:495-504. doi: $10.1007 /$ s1 1060-017-2375-2

25. Macdonald DR, Cascino TL, Schold SC, Cairncross JG. Response criteria for phase II studies of supratentorial malignant glioma. J Clin Oncol Off J Am Soc Clin Oncol. (1990) 8:1277-80. doi: 10.1200/JCO.1990.8.7.1277
26. Wen PY, Macdonald DR, Reardon DA, Cloughesy TF, Sorensen AG, Galanis E, et al. Updated response assessment criteria for high-grade gliomas: response assessment in neuro-oncology working group. J Clin Oncol Off J Am Soc Clin Oncol. (2010) 28:1963-72. doi: 10.1200/JCO.2009.26.3541

27. Okada H, Weller M, Huang R, Finocchiaro G, Gilbert MR, Wick $\mathrm{W}$, et al. Immunotherapy response assessment in neuro-oncology: a report of the RANO working group. Lancet Oncol. (2015) 16:e534-42. doi: 10.1016/S1470-2045(15)00088-1

28. Eisele SC, Wen PY, Lee EQ. Assessment of brain tumor response: RANO and its offspring. Curr Treat Options Oncol. (2016) 17:35. doi: $10.1007 / \mathrm{s} 11864-016-0413-5$

29. Chen W. Clinical applications of PET in brain tumors. J Nucl Med Off Publ Soc Nucl Med. (2007) 48:1468-81. doi: 10.2967/jnumed.106.037689

30. Verger A, Langen K-J. PET Imaging in glioblastoma: use in clinical Practice. In: De Vleeschouwer S, editor. Glioblastoma. Brisbane, AU: Codon Publications (2017) Available online at: http://www.ncbi.nlm.nih.gov/books/ NBK469986/ (accessedDec 10, 2018).

31. Delbeke D, Meyerowitz C, Lapidus RL, Maciunas RJ, Jennings MT, Moots PL, et al. Optimal cutoff levels of F-18 fluorodeoxyglucose uptake in the differentiation of low-grade from high-grade brain tumors with PET. Radiology. (1995) 195:47-52. doi: 10.1148/radiology.195.1. 7892494

32. Dunet V, Pomoni A, Hottinger A, Nicod-Lalonde M, Prior JO. Performance of $18 \mathrm{~F}$-FET versus $18 \mathrm{~F}-\mathrm{FDG}-\mathrm{PET}$ for the diagnosis and grading of brain tumors: systematic review and meta-analysis. Neuro Oncol. (2016) 18:42634. doi: 10.1093/neuonc/nov148

33. Hustinx R, Smith RJ, Benard F, Bhatnagar A, Alavi A. Can the standardized uptake value characterize primary brain tumors on FDG-PET? Eur J Nucl Med. (1999) 26:1501-9. doi: 10.1007/s002590050487

34. Omuro AM, Leite CC, Mokhtari K, Delattre J-Y. Pitfalls in the diagnosis of brain tumours. Lancet Neurol. (2006) 5:937-48. doi: 10.1016/S1474-4422(06)70597-X

35. Kosaka N, Tsuchida T, Uematsu H, Kimura H, Okazawa H, Itoh H. 18F-FDG PET of common enhancing malignant brain tumors. Am J Roentgenol. (2008) 190:W365-9. doi: 10.2214/AJR.07.2660

36. Yamashita K, Yoshiura T, Hiwatashi A, Togao O, Yoshimoto $\mathrm{K}$, Suzuki SO, et al. Differentiating primary CNS lymphoma from glioblastoma multiforme: assessment using arterial spin labeling, diffusion-weighted imaging, and ${ }^{18} \mathrm{~F}$-fluorodeoxyglucose positron emission tomography. Neuroradiology. (2013) 55:135-43. doi: 10.1007/s00234-0121089-6

37. Levivier M, Goldman S, Pirotte B, Brucher JM, Balériaux D, Luxen A, et al. Diagnostic yield of stereotactic brain biopsy guided by positron emission tomography with [18F]fluorodeoxyglucose. J Neurosurg. (1995) 82:445-52. doi: 10.3171/jns.1995.82.3.0445

38. Patronas NJ, Di Chiro G, Brooks RA, DeLaPaz RL, Kornblith PL, Smith $\mathrm{BH}$, et al. Work in progress: [18F] fluorodeoxyglucose and positron emission tomography in the evaluation of radiation necrosis of the brain. Radiology. (1982) 144:885-9. doi: 10.1148/radiology.144.4. 6981123

39. Di Chiro G, Oldfield E, Wright D, De Michele D, Katz D, Patronas N, et al. Cerebral necrosis after radiotherapy and/or intraarterial chemotherapy for brain tumors: PET and neuropathologic studies. Am J Roentgenol. (1988) 150:189-97. doi: 10.2214/ajr.150.1.189

40. Doyle WK, Budinger TF, Valk PE, Levin VA, Gutin PH. Differentiation of cerebral radiation necrosis from tumor recurrence by [18F]FDG and $82 \mathrm{Rb}$ positron emission tomography. J Comput Assist Tomogr. (1987) 11:563-70. doi: 10.1097/00004728-198707000-00001

41. Kim EE, Chung SK, Haynie TP, Kim CG, Cho BJ, Podoloff DA, et al. Differentiation of residual or recurrent tumors from post-treatment changes with F-18 FDG PET. Radiographics. (1992) 12:269-79. doi: 10.1148/radiographics.12.2. 1561416

42. Thompson TP, Lunsford LD, Kondziolka D. Distinguishing recurrent tumor and radiation necrosis with positron emission tomography versus stereotactic biopsy. Stereotact Funct Neurosurg. (1999) 73:9-14. doi: $10.1159 / 000029743$ 
43. Ricci PE, Karis JP, Heiserman JE, Fram EK, Bice AN, Drayer BP. Differentiating recurrent tumor from radiation necrosis: time for reevaluation of positron emission tomography? AJNR Am J Neuroradiol. (1998) 19:407-13.

44. Nihashi T, Dahabreh IJ, Terasawa T. Diagnostic accuracy of PET for recurrent glioma diagnosis: a meta-analysis. AJNR Am J Neuroradiol. (2013) 34:944-50, S1-11. doi: 10.3174/ajnr.A3324

45. Olivero WC, Dulebohn SC, Lister JR. The use of PET in evaluating patients with primary brain tumours: is it useful? J Neurol Neurosurg Psychiatry. (1995) 58:250-2. doi: 10.1136/jnnp.58.2.250

46. De Witte O, Lefranc F, Levivier M, Salmon I, Brotchi J, Goldman S. FDG-PET as a prognostic factor in high-grade astrocytoma. J Neurooncol. (2000) 49:157-63. doi: 10.1023/a:1026518002800

47. Spence AM, Muzi M, Graham MM, O’Sullivan F, Link JM, Lewellen TK, et al. 2-[18F]Fluoro-2-deoxyglucose and Glucose uptake in malignant gliomas before and after radiotherapy: correlation with Outcome. Clin Cancer Res. (2002) 8:971-9.

48. Padma MV, Said S, Jacobs M, Hwang DR, Dunigan K, Satter M, et al. Prediction of pathology and survival by FDG PET in gliomas. J Neurooncol. (2003) 64:227-37. doi: 10.1023/A:1025665820001

49. Colavolpe C, Metellus P, Mancini J, Barrie M, Béquet-Boucard C, Figarella-Branger D, et al. Independent prognostic value of pre-treatment 18-FDG-PET in high-grade gliomas. J Neurooncol. (2012) 107:527-35. doi: 10.1007/s11060-011-0771-6

50. Santra A, Kumar R, Sharma P, Bal C, Julka PK, Malhotra A. F-18 FDG PETCT for predicting survival in patients with recurrent glioma: a prospective study. Neuroradiology. (2011) 53:1017-24. doi: 10.1007/s00234-0110898-3

51. Leiva-Salinas C, Schiff D, Flors L, Patrie JT, Rehm PK. FDG PET/MR Imaging Coregistration helps predict survival in patients with glioblastoma and radiologic progression after standard of care Treatment. Radiology. (2017) 283:508-14. doi: 10.1148/radiol.2016161172

52. Charnley N, West CM, Barnett CM, Brock C, Bydder GM, Glaser $\mathrm{M}$, et al. Early change in glucose metabolic rate measured using FDG-PET in patients with high-grade glioma predicts response to temozolomide but not temozolomide plus radiotherapy. Int $J$ Radiat Oncol Biol Phys. (2006) 66:331-8. doi: 10.1016/j.ijrobp.2006. 04.043

53. Colavolpe C, Chinot O, Metellus P, Mancini J, Barrie M, Bequet-Boucard $\mathrm{C}$, et al. FDG-PET predicts survival in recurrent high-grade gliomas treated with bevacizumab and irinotecan. Neuro Oncol. (2012) 14:649-57. doi: 10.1093/neuonc/nos012

54. Bolcaen J, Acou M, Descamps B, Kersemans K, Deblaere K, Vanhove C, et al. PET for therapy response assessment in glioblastoma. In: De Vleeschouwer S, editor. Glioblastoma. Brisbane, AU: Codon Publications (2017). Available online at: http://www.ncbi.nlm.nih.gov/books/NBK469988/ (accessed December 11, 2018)

55. Douglas JG, Stelzer KJ, Mankoff DA, Tralins KS, Krohn KA, Muzi $\mathrm{M}$, et al. [F-18]-fluorodeoxyglucose positron emission tomography for targeting radiation dose escalation for patients with glioblastoma multiforme: clinical outcomes and patterns of failure. Int $J$ Radiat Oncol Biol Phys. (2006) 64:886-91. doi: 10.1016/j.ijrobp.2005. 08.013

56. Spence AM, Muzi M, Mankoff DA, O’Sullivan SF, Link JM, Lewellen TK, et al. 18F-FDG PET of Gliomas at delayed intervals: improved distinction between tumor and normal gray Matter. J Nucl Med. (2004) 45:1653-9.

57. Herholz K. Brain Tumors: an update on clinical PET Research in Gliomas. Semin Nucl Med. (2017) 47:5-17. doi: 10.1053/j.semnuclmed.2016.09.004

58. Hojjati M, Badve C, Garg V, Tatsuoka C, Rogers L, Sloan A, et al. Role of FDG-PET/MRI, FDG-PET/CT, and Dynamic susceptibility contrast perfusion MRI in differentiating radiation necrosis from tumor recurrence in Glioblastomas. J Neuroimaging. (2018) 28:118-25. doi: 10.1111/jon.12460

59. Wong TZ, Turkington TG, Hawk TC, Coleman RE. PET and brain tumor image fusion. Cancer J Sudbury Mass. (2004) 10:234-42. doi: 10.1097/00130404-20040700000004

60. Hassanzadeh C, Rao YJ, Chundury A, Rowe J, Ponisio MR, Sharma A, et al. Multiparametric MRI and [18F]Fluorodeoxyglucose positron emission tomography imaging is a potential prognostic imaging biomarker in recurrent Glioblastoma. Front Oncol. (2017) 7:178. doi: 10.3389/fonc. 2017.00178

61. Chiang GC, Galla N, Ferraro R, Kovanlikaya I. The Added prognostic value of metabolic tumor size on FDG-PET at first suspected recurrence of glioblastoma Multiforme. J Neuroimaging Off J Am Soc Neuroimaging. (2017) 27:243-7. doi: 10.1111/jon.12386

62. Glunde K, Bhujwalla ZM, Ronen SM. Choline metabolism in malignant transformation. Nat Rev Cancer. (2011) 11:835-48. doi: 10.1038/nrc3162

63. Ohtani T, Kurihara H, Ishiuchi S, Saito N, Oriuchi N, Inoue T, et al. Brain tumour imaging with carbon-11 choline: comparison with FDG PET and gadolinium-enhanced MR imaging. Eur J Nucl Med. (2001) 28:1664-70. doi: $10.1007 /$ s002590100620

64. Kwee SA, Ko JP, Jiang CS, Watters MR, Coel MN. Solitary brain lesions enhancing at MR imaging: evaluation with fluorine 18 fluorocholine PET. Radiology. (2007) 244:557-65. doi: 10.1148/radiol.2442060898

65. Tian M, Zhang H, Oriuchi N, Higuchi T, Endo K. Comparison of 11C-choline PET and FDG PET for the differential diagnosis of malignant tumors. Eur J Nucl Med Mol Imaging. (2004) 31:1064-72. doi: 10.1007/s00259-004-1496-y

66. Mertens K, Bolcaen J, Ham H, Deblaere K, Van den Broecke C, Boterberg $\mathrm{T}$, et al. The optimal timing for imaging brain tumours and other brain lesions with 18F-labelled fluoromethylcholine: a dynamic positron emission tomography study. Nucl Med Commun. (2012) 33:954-9. doi: 10.1097/MNM.0b013e328355b6f5

67. Spaeth N, Wyss MT, Weber B, Scheidegger S, Lutz A, Verwey J, et al. Uptake of 18F-Fluorocholine, 18F-Fluoroethyl-l-Tyrosine, and 18F-FDG in Acute cerebral radiation injury in the rat: implications for separation of radiation necrosis from tumor Recurrence. J Nucl Med. (2004) 45:1931-8.

68. Tan H, Chen L, Guan Y, Lin X. Comparison of MRI, F-18 FDG, and 11Ccholine PET/CT for their potentials in differentiating brain tumor recurrence from brain tumor necrosis following radiotherapy. Clin Nucl Med. (2011) 36:978-81. doi: 10.1097/RLU.0b013e31822f68a6

69. Galldiks N, Langen K-J. Amino Acid PET - an imaging option to identify treatment response, posttherapeutic effects, and tumor recurrence? Front Neurol. (2016) 7:120. doi: 10.3389/fneur.2016.00120

70. Jager PL, Vaalburg W, Pruim J, Vries EGE de, Langen K-J, Piers DA. Radiolabeled Amino acids: basic aspects and clinical applications in Oncology*. J Nucl Med. (2001) 42:432-45.

71. Miyagawa T, Oku T, Uehara H, Desai R, Beattie B, Tjuvajev J, et al. 'Facilitated' amino acid transport is upregulated in brain tumors. J Cereb Blood Flow Metab Off J Int Soc Cereb Blood Flow Metab. (1998) 18:500-9. doi: 10.1097/00004647-199805000-00005

72. Albert NL, Weller M, Suchorska B, Galldiks N, Soffietti R, Kim MM, et al. Response Assessment in Neuro-Oncology working group and European Association for Neuro-Oncology recommendations for the clinical use of PET imaging in gliomas. Neuro Oncol. (2016) 18:1199-208. doi: 10.1093/neuonc/now058

73. Chung J-K, Kim YK, Kim S, Lee YJ, Paek S, Yeo JS, et al. Usefulness of $11 \mathrm{C}$-methionine PET in the evaluation of brain lesions that are hypoor isometabolic on 18F-FDG PET. Eur J Nucl Med Mol Imaging. (2002) 29:176-82. doi: 10.1007/s00259-001-0690-4

74. Lopci E, Riva M, Olivari L, Raneri F, Soffietti R, Piccardo A, et al. Prognostic value of molecular and imaging biomarkers in patients with supratentorial glioma. Eur J Nucl Med Mol Imaging. (2017) 44:1155-64. doi: 10.1007/s00259-017-3618-3

75. Pirotte B, Goldman S, Massager N, David P, Wikler D, Lipszyc M, et al. Combined use of $18 \mathrm{~F}$-fluorodeoxyglucose and 11C-methionine in 45 positron emission tomography-guided stereotactic brain biopsies. $J$ Neurosurg. (2004) 101:476-83. doi: 10.3171/jns.2004.101.3.0476

76. Pirotte B, Goldman S, Massager N, David P, Wikler D, Vandesteene A, et al. Comparison of 18F-FDG and 11C-methionine for PET-guided stereotactic brain biopsy of gliomas. J Nucl Med Off Publ Soc Nucl Med. (2004) 45:1293-8.

77. TAKENAKA S, Asano Y, Shinoda J, Nomura Y, Yonezawa S, MIWA $\mathrm{K}$, et al. Comparison of 11C-Methionine, 11C-Choline, and $18 \mathrm{~F}$ Fluorodeoxyglucose-positron emission tomography for distinguishing glioma recurrence from radiation Necrosis. Neurol Med Chir. (2014) 54:2809. doi: 10.2176/nmc.oa2013-0117 
78. Kim YH, Oh SW, Lim YJ, Park C-K, Lee S-H, Kang KW, et al. Differentiating radiation necrosis from tumor recurrence in high-grade gliomas: assessing the efficacy of 18F-FDG PET, 11C-methionine PET and perfusion MRI. Clin Neurol Neurosurg. (2010) 112:758-65. doi: 10.1016/j.clineuro.2010.06.005

79. Lee IH, Piert M, Gomez-Hassan D, Junck L, Rogers L, Hayman $\mathrm{J}$, et al. Association of 11C-Methionine PET uptake with site of failure after concurrent temozolomide and radiation for primary glioblastoma multiforme. Int J Radiat Oncol Biol Phys. (2009) 73:479-85. doi: 10.1016/j.ijrobp.2008.04.050

80. Miwa K, Matsuo M, Ogawa S, Shinoda J, Yokoyama K, Yamada J, et al. Re-irradiation of recurrent glioblastoma multiforme using 11C-methionine PET/CT/MRI image fusion for hypofractionated stereotactic radiotherapy by intensity modulated radiation therapy. Radiat Oncol Lond Engl. (2014)9:181. doi: 10.1186/1748-717X-9-181

81. Grosu AL, Weber WA, Franz M, Stärk S, Piert M, Thamm R, et al. Reirradiation of recurrent high-grade gliomas using amino acid PET (SPECT)/CT/MRI image fusion to determine gross tumor volume for stereotactic fractionated radiotherapy. Int J Radiat Oncol Biol Phys. (2005) 63:511-9. doi: 10.1016/j.ijrobp.2005.01.056

82. Galldiks N, Kracht LW, Burghaus L, Thomas A, Jacobs AH, Heiss W-D, et al. Use of 11C-methionine PET to monitor the effects of temozolomide chemotherapy in malignant gliomas. Eur J Nucl Med Mol Imaging. (2006) 33:516-24. doi: 10.1007/s00259-005-0002-5

83. Beppu T, Terasaki K, Sasaki T, Sato Y, Tomabechi M, Kato K, et al. MRI and 11C-methyl-L-methionine PET Differentiate bevacizumab true responders after initiating therapy for recurrent Glioblastoma. Clin Nucl Med. (2016) 41:852-7. doi: 10.1097/RLU.0000000000001377

84. Calabria F, Cascini GL. Current status of 18F-DOPA PET imaging in the detection of brain tumor recurrence. Hell J Nucl Med. (2015) 18:152-6. doi: $10.1967 / \mathrm{s} 0024499100211$

85. Heiss W-D, Wienhard K, Wagner R, Lanfermann H, Thiel A, Herholz K, et al. F-Dopa as an Amino acid tracer to detect brain Tumors. J Nucl Med. (1996) 37:1180-2.

86. Youland RS, Kitange GJ, Peterson TE, Pafundi DH, Ramiscal JA, Pokorny JL, et al. The role of LAT1 in 18F-DOPA uptake in malignant gliomas. $J$ Neurooncol. (2013) 111:11-8. doi: 10.1007/s11060-012-0986-1

87. Dadone-Montaudié B, Ambrosetti D, Dufour M, Darcourt J, Almairac F, Coyne J, et al. [18F] FDOPA standardized uptake values of brain tumors are not exclusively dependent on LAT1 expression. PLoS ONE. (2017) 12:e0184625. doi: 10.1371/journal.pone.0184625

88. Schiepers C, Chen W, Cloughesy T, Dahlbom M, Huang S-C. 18FFDOPA kinetics in brain tumors. J Nucl Med. (2007) 48:1651-61. doi: 10.2967/jnumed.106.039321

89. Bell C, Dowson N, Puttick S, Gal Y, Thomas P, Fay M, et al. Increasing feasibility and utility of (18)F-FDOPA PET for the management of glioma. Nucl Med Biol. (2015) 42:788-95. doi: 10.1016/j.nucmedbio.2015. 06.001

90. Talbot J-N, Kerrou K, Montravers F, Nataf V, Chevalme Y. FDOPA PET has clinical utility in brain tumour imaging: a proposal for a revision of the recent EANM guidelines. Eur J Nucl Med Mol Imaging. (2007) 34:1131-2. doi: 10.1007/s00259-007-0400-y

91. Becherer A, Karanikas G, Szabó M, Zettinig G, Asenbaum S, Marosi C, et al. Brain tumour imaging with PET: a comparison between [18F]fluorodopa and [11C]methionine. Eur J Nucl Med Mol Imaging. (2003) 30:1561-7. doi: 10.1007/s00259-003-1259-1

92. Fueger BJ, Czernin J, Cloughesy T, Silverman DH, Geist CL, Walter MA, et al. Correlation of 6-18F-fluoro-L-dopa PET uptake with proliferation and tumor grade in newly diagnosed and recurrent gliomas. $J \mathrm{Nucl}$ Med Off Publ Soc Nucl Med. (2010) 51:1532-8. doi: 10.2967/jnumed.110. 078592

93. Janvier L, Olivier P, Blonski M, Morel O, Vignaud J-M, Karcher G, et al. Correlation of SUV-Derived indices with tumoral aggressiveness of gliomas in static 18F-FDOPA PET: use in Clinical Practice. Clin Nucl Med. (2015) 40:e429-35. doi: 10.1097/RLU.0000000000000897

94. Bund C, Heimburger C, Imperiale A, Lhermitte B, Chenard M-P, Lefebvre F, et al. FDOPA PET-CT of nonenhancing brain tumors. Clin Nucl Med. (2017) 42:250-7. doi: 10.1097/RLU.0000000000001540
95. Chen W, Silverman DHS, Delaloye S, Czernin J, Kamdar N, Pope W, et al. 18F-FDOPA PET imaging of brain tumors: comparison study with 18F-FDG PET and evaluation of diagnostic accuracy. J Nucl Med Off Publ Soc Nucl Med. (2006) 47:904-11.

96. Kratochwil C, Combs SE, Leotta K, Afshar-Oromieh A, Rieken S, Debus $\mathrm{J}$, et al. Intra-individual comparison of ${ }^{18} \mathrm{~F}$-FET and ${ }^{18} \mathrm{~F}$-DOPA in PET imaging of recurrent brain tumors. Neuro Oncol. (2014) 16:434-40. doi: 10.1093/neuonc/not199

97. Pafundi DH, Laack NN, Youland RS, Parney IF, Lowe VJ, Giannini $\mathrm{C}$, et al. Biopsy validation of 18F-DOPA PET and biodistribution in gliomas for neurosurgical planning and radiotherapy target delineation: results of a prospective pilot study. Neuro Oncol. (2013) 15:1058-67. doi: 10.1093/neuonc/not002

98. Kosztyla R, Chan EK, Hsu F, Wilson D, Ma R, Cheung A, et al. High-grade glioma radiation therapy target volumes and patterns of failure obtained from magnetic resonance imaging and 18F-FDOPA positron emission tomography delineations from multiple observers. Int J Radiat Oncol Biol Phys. (2013) 87:1100-6. doi: 10.1016/j.ijrobp.2013. 09.008

99. Cicone F, Filss CP, Minniti G, Rossi-Espagnet C, Papa A, Scaringi $\mathrm{C}$, et al. Volumetric assessment of recurrent or progressive gliomas: comparison between F-DOPA PET and perfusion-weighted MRI. Eur J Nucl Med Mol Imaging. (2015) 42:905-15. doi: 10.1007/s00259-0153018-5

100. Karunanithi S, Sharma P, Kumar A, Khangembam BC, Bandopadhyaya GP, Kumar R, et al. 18F-FDOPA PET/CT for detection of recurrence in patients with glioma: prospective comparison with 18F-FDG PET/CT. Eur J Nucl Med Mol Imaging. (2013) 40:1025-35. doi: 10.1007/s00259-0132384-0

101. Herrmann K, Czernin J, Cloughesy T, Lai A, Pomykala KL, Benz MR, et al. Comparison of visual and semiquantitative analysis of 18F-FDOPAPET/CT for recurrence detection in glioblastoma patients. Neuro Oncol. (2014) 16:603-9. doi: 10.1093/neuonc/not166

102. Ledezma CJ, Chen W, Sai V, Freitas B, Cloughesy T, Czernin J, et al. 18FFDOPA PET/MRI fusion in patients with primary/recurrent gliomas: initial experience. Eur J Radiol. (2009) 71:242-8. doi: 10.1016/j.ejrad.2008.04.018

103. Sala Q, Metellus P, Taieb D, Kaphan E, Figarella-Branger D, Guedj E. 18FDOPA, a clinically available PET tracer to study brain inflammation? Clin Nucl Med. (2014) 39:e283-5. doi: 10.1097/RLU.0000000000000383

104. Karunanithi S, Sharma P, Kumar A, Gupta DK, Khangembam BC, Ballal S, et al. Can (18)F-FDOPA PET/CT predict survival in patients with suspected recurrent glioma? A prospective study. Eur J Radiol. (2014) 83:219-25. doi: 10.1016/j.ejrad.2013. 09.004

105. Villani V, Carapella CM, Chiaravalloti A, Terrenato I, Piludu F, Vidiri A, et al. The Role of PET [18F]FDOPA in evaluating low-grade Glioma. Anticancer Res. (2015) 35:5117-22.

106. Rossi Espagnet MC, Romano A, Mancuso V, Cicone F, Napolitano A, Scaringi $\mathrm{C}$, et al. Multiparametric evaluation of low grade gliomas at follow-up: comparison between diffusion and perfusion MR with (18)F-FDOPA PET. Br J Radiol. (2016) 89:20160476. doi: 10.1259/bjr.20160476

107. Verger A, Metellus P, Sala Q, Colin C, Bialecki E, Taieb D, et al. IDH mutation is paradoxically associated with higher 18F-FDOPA PET uptake in diffuse grade II and grade III gliomas. Eur J Nucl Med Mol Imaging. (2017) 44:1306-11. doi: 10.1007/s00259-017-3668-6

108. Sibel I, Guillaume G, Fabien R, Marie B, Sophie P, Mohammad B C, et al. A high ${ }^{18}$ F-FDOPA uptake is associated with a slow growth rate in diffuse grade II-III gliomas. Br J Radiol. (2017) 20170803. doi: 10.1259/bjr.20170803

109. Schwarzenberg J, Czernin J, Cloughesy TF, Ellingson BM, Pope WB, Grogan T, et al. Treatment response evaluation using 18F-FDOPA PET in patients with recurrent malignant glioma on bevacizumab therapy. Clin Cancer Res Off J Am Assoc Cancer Res. (2014) 20:3550-9. doi: 10.1158/1078-0432.CCR-13-1440

110. Harris RJ, Cloughesy TF, Pope WB, Nghiemphu PL, Lai A, Zaw T, et al. 18F-FDOPA and 18F-FLT positron emission tomography parametric response maps predict response in recurrent malignant gliomas treated with bevacizumab. Neuro Oncol. (2012) 14:1079-89. doi: 10.1093/neuonc/nos141 
111. Karavaeva E, Harris RJ, Leu K, Shabihkhani M, Yong WH, Pope WB, et al. Relationship Between [18F]FDOPA PET uptake, apparent diffusion coefficient (ADC), and proliferation rate in recurrent malignant Gliomas. Mol Imaging Biol MIB Off Publ Acad Mol Imaging. (2015) 17:434-42. doi: $10.1007 /$ s11307-014-0807-3

112. Coenen HH, Elsinga PH, Iwata R, Kilbourn MR, Pillai MRA, Rajan MGR, et al. Fluorine-18 radiopharmaceuticals beyond [18F]FDG for use in oncology and neurosciences. Nucl Med Biol. (2010) 37:727-40. doi: 10.1016/j.nucmedbio.2010.04.185

113. Grosu A-L, Astner ST, Riedel E, Nieder C, Wiedenmann N, Heinemann F, et al. An interindividual comparison of O-(2-[18F]fluoroethyl)-L-tyrosine (FET)- and L-[methyl-11C]methionine (MET)-PET in patients with brain gliomas and metastases. Int J Radiat Oncol Biol Phys. (2011) 81:1049-58. doi: 10.1016/j.ijrobp.2010.07.002

114. Lapa C, Linsenmann T, Monoranu CM, Samnick S, Buck AK, Bluemel C, et al. Comparison of the amino acid tracers 18F-FET and 18F-DOPA in highgrade glioma patients. J Nucl Med Off Publ Soc Nucl Med. (2014) 55:1611-6. doi: 10.2967/jnumed.114.140608

115. Floeth FW, Pauleit D, Wittsack H-J, Langen KJ, Reifenberger G, Hamacher K, et al. Multimodal metabolic imaging of cerebral gliomas: positron emission tomography with [18F]fluoroethyl-L-tyrosine and magnetic resonance spectroscopy. J Neurosurg. (2005) 102:318-27. doi: $10.3171 /$ jns.2005.102.2.0318

116. Filss CP, Galldiks N, Stoffels G, Sabel M, Wittsack HJ, Turowski B, et al. Comparison of 18F-FET PET and perfusion-weighted MR imaging: a PET/MR imaging hybrid study in patients with brain tumors. J Nucl Med Off Publ Soc Nucl Med. (2014) 55:540-5. doi: 10.2967/jnumed.113.129007

117. Lundemann M, Costa JC, Law I, Engelholm SA, Muhic A, Poulsen HS, et al. Patterns of failure for patients with glioblastoma following O-(2-[18F]fluoroethyl)-L-tyrosine PET- and MRI-guided radiotherapy. Radiother Oncol J Eur Soc Ther Radiol Oncol. (2017) 122:380-6. doi: 10.1016/j.radonc.2017.01.002

118. Buchmann N, Kläsner B, Gempt J, Bauer JS, Pyka T, Delbridge C, et al. (18)F-Fluoroethyl-1-Thyrosine positron emission tomography to delineate tumor residuals after glioblastoma resection: a comparison with standard postoperative magnetic resonance Imaging. World Neurosurg. (2016) 89:420-6. doi: 10.1016/j.wneu.2016.02.032

119. Galldiks N, Lohmann P, Albert NL, Tonn JC, Langen KJ. Current status of PET imaging in neuro-oncology. Neuro Oncol Adv. (2019) 1:vdz010. doi: 10.1093/noajnl/vdz010

120. Rapp M, Heinzel A, Galldiks N, Stoffels G, Felsberg J, Ewelt C, et al. Diagnostic performance of 18F-FET PET in newly diagnosed cerebral lesions suggestive of glioma. J Nucl Med. (2013) 54:229-35. doi: 10.2967/jnumed.112.109603

121. Pöpperl G, Kreth FW, Herms J, Koch W, Mehrkens JH, Gildehaus FJ, et al. Analysis of 18F-FET PET for grading of recurrent gliomas: is evaluation of uptake kinetics superior to standard methods? J Nucl Med Off Publ Soc Nucl Med. (2006) 47:393-403.

122. Pöpperl G, Kreth FW, Mehrkens JH, Herms J, Seelos K, Koch W, et al. FET PET for the evaluation of untreated gliomas: correlation of FET uptake and uptake kinetics with tumour grading. Eur J Nucl Med Mol Imaging. (2007) 34:1933-42. doi: 10.1007/s00259-007-0534-y

123. Albert NL, Winkelmann I, Suchorska B, Wenter V, Schmid-Tannwald C, Mille E, et al. Early static (18)F-FET-PET scans have a higher accuracy for glioma grading than the standard 20-40 min scans. Eur J Nucl Med Mol Imaging. (2016) 43:1105-14. doi: 10.1007/s00259-0153276-2

124. Lopez WOC, Cordeiro JG, Albicker U, Doostkam S, Nikkhah G, Kirch $\mathrm{RD}$, et al. Correlation of (18)F-fluoroethyl tyrosine positron-emission tomography uptake values and histomorphological findings by stereotactic serial biopsy in newly diagnosed brain tumors using a refined software tool. Onco Targets Ther. (2015) 8:3803-15. doi: 10.2147/OTT.S87126

125. Pöpperl G, Götz C, Rachinger W, Gildehaus F-J, Tonn J-C, Tatsch K. Value of O-(2-[18F]fluoroethyl)- L-tyrosine PET for the diagnosis of recurrent glioma. Eur J Nucl Med Mol Imaging. (2004) 31:1464-70. doi: 10.1007/s00259-004-1590-1

126. Mehrkens JH, Pöpperl G, Rachinger W, Herms J, Seelos K, Tatsch K, et al. The positive predictive value of $\mathrm{O}-(2-[18 \mathrm{~F}]$ fluoroethyl)-L-tyrosine (FET)
PET in the diagnosis of a glioma recurrence after multimodal treatment. $J$ Neurooncol. (2008) 88:27-35. doi: 10.1007/s11060-008-9526-4

127. Rachinger W, Goetz C, Pöpperl G, Gildehaus FJ, Kreth FW, Holtmannspötter $M$, et al. Positron emission tomography with O-(2[18F]fluoroethyl)-l-tyrosine versus magnetic resonance imaging in the diagnosis of recurrent gliomas. Neurosurgery. (2005) 57:505-11. Discussion 505-11. doi: 10.1227/01.NEU.0000171642.49553.B0

128. Calcagni ML, Galli G, Giordano A, Taralli S, Anile C, Niesen A, et al. Dynamic O-(2-[18F]fluoroethyl)-L-tyrosine (F-18 FET) PET for glioma grading: assessment of individual probability of malignancy. Clin $\mathrm{Nucl} \mathrm{Med}$. (2011) 36:841-7. doi: 10.1097/RLU.0b013e3182291b40

129. Galldiks N, Stoffels G, Filss C, Rapp M, Blau T, Tscherpel C, et al. The use of dynamic O-(2-18F-fluoroethyl)-1-tyrosine PET in the diagnosis of patients with progressive and recurrent glioma. Neuro Oncol. (2015) 17:1293-300. doi: 10.1093/neuonc/nov088

130. Galldiks N, Dunkl V, Stoffels G, Hutterer M, Rapp M, Sabel M, et al. Diagnosis of pseudoprogression in patients with glioblastoma using O(2-[18F]fluoroethyl)-L-tyrosine PET. Eur J Nucl Med Mol Imaging. (2015) 42:685-95. doi: 10.1007/s00259-014-2959-4

131. Kebir S, Fimmers R, Galldiks N, Schäfer N, Mack F, Schaub C, et al. Late Pseudoprogression in glioblastoma: diagnostic value of dynamic O-(2[18F]fluoroethyl)-L-Tyrosine PET. Clin Cancer Res Off J Am Assoc Cancer Res. (2016) 22:2190-6. doi: 10.1158/1078-0432.CCR-15-1334

132. Pauleit D, Floeth F, Hamacher K, Riemenschneider MJ, Reifenberger G, Müller H-W, et al. O-(2-[18F]fluoroethyl)-L-tyrosine PET combined with MRI improves the diagnostic assessment of cerebral gliomas. Brain J Neurol. (2005) 128(Pt 3):678-87. doi: 10.1093/brain/awh399

133. Floeth FW, Pauleit D, Sabel M, Reifenberger G, Stoffels G, Stummer W, et al. 18F-FET PET differentiation of ring-enhancing brain lesions. J Nucl Med Off Publ Soc Nucl Med. (2006) 47:776-82.

134. Hutterer M, Nowosielski M, Putzer D, la Fougère C, Virgolini IJ, Jacobs, AH, et al. Response to "Reply to [18F]-fluoro-ethyl-L-tyrosine PET: a valuable diagnostic tool in neuro-oncology, but not all that glitters is glioma" by Hutterer et al. Neuro Oncol. (2013) 15:814-5. doi: 10.1093/neuonc/not081

135. Harat M, Małkowski B, Makarewicz R. Pre-irradiation tumour volumes defined by MRI and dual time-point FET-PET for the prediction of glioblastoma multiforme recurrence: a prospective study. Radiother Oncol. (2016) 120:241-7. doi: 10.1016/j.radonc.2016.06.004

136. Piroth MD, Holy R, Pinkawa M, Stoffels G, Kaiser HJ, Galldiks N, et al. Prognostic impact of postoperative, pre-irradiation (18)F-fluoroethyl-ltyrosine uptake in glioblastoma patients treated with radiochemotherapy. Radiother Oncol J Eur Soc Ther Radiol Oncol. (2011) 99:218-24. doi: 10.1016/j.radonc.2011.03.006

137. Suchorska B, Jansen NL, Linn J, Kretzschmar H, Janssen H, Eigenbrod S, et al. Biological tumor volume in 18FET-PET before radiochemotherapy correlates with survival in GBM. Neurology. (2015) 84:710-9. doi: 10.1212/WNL.0000000000001262

138. Poulsen SH, Urup T, Grunnet K, Christensen IJ, Larsen VA, Jensen ML, et al. The prognostic value of FET PET at radiotherapy planning in newly diagnosed glioblastoma. Eur J Nucl Med Mol Imaging. (2017) 44:373-81. doi: 10.1007/s00259-016-3494-2

139. Piroth MD, Pinkawa M, Holy R, Klotz J, Nussen S, Stoffels G, et al. Prognostic value of early $[18 \mathrm{~F}]$ fluoroethyltyrosine positron emission tomography after radiochemotherapy in glioblastoma multiforme. Int J Radiat Oncol Biol Phys. (2011) 80:176-84. doi: 10.1016/j.ijrobp.2010.01.055

140. Galldiks N, Langen K-J, Holy R, Pinkawa M, Stoffels G, Nolte KW, et al. Assessment of treatment response in patients with glioblastoma using O-(218F-fluoroethyl)-L-tyrosine PET in comparison to MRI. J Nucl Med Off Publ Soc Nucl Med. (2012) 53:1048-57. doi: 10.2967/jnumed.111.098590

141. Piroth MD, Liebenstund S, Galldiks N, Stoffels G, Shah NJ, Eble MJ, et al. Monitoring of radiochemotherapy in patients with glioblastoma using O-(2- ${ }^{18}$ Fluoroethyl $)$-L-tyrosine positron emission tomography: is dynamic imaging helpful? Mol Imaging. (2013) 12:388-95. doi: 10.2310/7290.2013.00056

142. Galldiks N, Rapp M, Stoffels G, Fink GR, Shah NJ, Coenen HH, et al. Response assessment of bevacizumab in patients with recurrent malignant glioma using [18F]Fluoroethyl-L-tyrosine PET in comparison to MRI. Eur J Nucl Med Mol Imaging. (2013) 40:22-33. doi: 10.1007/s00259-012-2251-4 
143. Hutterer M, Nowosielski M, Putzer D, Waitz D, Tinkhauser G, Kostron $\mathrm{H}$, et al. O-(2-18F-fluoroethyl)-L-tyrosine PET predicts failure of antiangiogenic treatment in patients with recurrent highgrade glioma. J Nucl Med Off Publ Soc Nucl Med. (2011) 52:856-64. doi: 10.2967/jnumed.110.086645

144. Heinzel A, Müller D, Langen K-J, Blaum M, Verburg FA, Mottaghy FM, et al. The use of O-(2-18F-fluoroethyl)-L-tyrosine PET for treatment management of bevacizumab and irinotecan in patients with recurrent high-grade glioma: a cost-effectiveness analysis. J Nucl Med Off Publ Soc Nucl Med. (2013) 54:1217-22. doi: 10.2967/jnumed.113.120089

145. Ceccon G, Lazaridis L, Stoffels G, Rapp M, Weber M, Blau T, et al. Use of FET PET in glioblastoma patients undergoing neurooncological treatment including tumour-treating fields: initial experience. Eur J Nucl Med Mol Imaging. (2018) 45:1626-35. doi: 10.1007/s00259-018-3992-5

146. Pyka T, Hiob D, Preibisch C, Gempt J, Wiestler B, Schlegel J, et al. Diagnosis of glioma recurrence using multiparametric dynamic 18F-fluoroethyl-tyrosine PET-MRI. Eur J Radiol. (2018) 103:32-7. doi: 10.1016/j.ejrad.2018.04.003

147. Kebir S, Khurshid Z, Gaertner FC, Essler M, Hattingen E, Fimmers R, et al. Unsupervised consensus cluster analysis of [18F]-fluoroethyl-L-tyrosine positron emission tomography identified textural features for the diagnosis of pseudoprogression in high-grade glioma. Oncotarget. (2017) 8:8294-304. doi: 10.18632/oncotarget.14166

148. Lohmann P, Lerche C, Bauer EK, Steger J, Stoffels G, Blau T, et al. Predicting IDH genotype in gliomas using FET PET radiomics. Sci Rep. (2018) 8:13328. doi: 10.1038/s41598-018-31806-7

149. Galldiks N, Langen K-J, Pope WB. From the clinician's point of view - What is the status quo of positron emission tomography in patients with brain tumors? Neuro Oncol. (2015) 17:1434-44. doi: 10.1093/neuonc/novl18

150. Herholz K, Langen K-J, Schiepers C, Mountz JM. Brain tumors. Semin Nucl Med. (2012) 42:356-70. doi: 10.1053/j.semnuclmed.2012.06.001

151. Jacobs AH, Thomas A, Kracht LW, Li H, Dittmar C, Garlip G, et al. 18F-fluoro-L-thymidine and 11C-methylmethionine as markers of increased transport and proliferation in brain tumors. J Nucl Med Off Publ Soc Nucl Med. (2005) 46:1948-58.

152. Choi SJ, Kim JS, Kim JH, Oh SJ, Lee JG, Kim CJ, et al. [18F]3'-deoxy-3'fluorothymidine PET for the diagnosis and grading of brain tumors. Eur $J$ Nucl Med Mol Imaging. (2005) 32:653-9. doi: 10.1007/s00259-004-1742-3

153. Chen W, Cloughesy T, Kamdar N, Satyamurthy N, Bergsneider M, Liau L, et al. Imaging proliferation in brain tumors with 18F-FLT PET: comparison with 18F-FDG. J Nucl Med Off Publ Soc Nucl Med. (2005) 46:945-52.

154. Enslow MS, Zollinger LV, Morton KA, Butterfield RI, Kadrmas DJ, Christian $\mathrm{PE}$, et al. Comparison of 18F-fluorodeoxyglucose and 18F-fluorothymidine PET in differentiating radiation necrosis from recurrent glioma. Clin Nucl Med. (2012) 37:854-61. doi: 10.1097/RLU.0b013e318262c76a

155. Idema AJS, Hoffmann AL, Boogaarts HD, Troost EGC, Wesseling P, Heerschap A, et al. 3'-Deoxy-3'-18F-fluorothymidine PET-derived proliferative volume predicts overall survival in high-grade glioma patients. J Nucl Med Off Publ Soc Nucl Med. (2012) 53:1904-10. doi: 10.2967/jnumed.112.105544

156. Schwarzenberg J, Czernin J, Cloughesy TF, Ellingson BM, Pope WB, Geist C, et al. 3'-deoxy-3'-18F-fluorothymidine PET and MRI for early survival predictions in patients with recurrent malignant glioma treated with bevacizumab. J Nucl Med Off Publ Soc Nucl Med. (2012) 53:29-36. doi: 10.2967/jnumed.111.092387

157. Chen W, Delaloye S, Silverman DHS, Geist C, Czernin J, Sayre J, et al. Predicting treatment response of malignant gliomas to bevacizumab and irinotecan by imaging proliferation with $[18 \mathrm{~F}]$ fluorothymidine positron emission tomography: a pilot study. J Clin Oncol Off J Am Soc Clin Oncol. (2007) 25:4714-21. doi: 10.1200/JCO.2006.10.5825

158. Wardak M, Schiepers C, Cloughesy TF, Dahlbom M, Phelps ME, Huang SC. ${ }^{18} \mathrm{~F}$-FLT and ${ }^{18} \mathrm{~F}$-FDOPA PET kinetics in recurrent brain tumors. Eur J Nucl Med Mol Imaging. (2014) 41:1199-209. doi: 10.1007/s00259-0132678-2

159. Bruehlmeier M, Roelcke U, Schubiger PA, Ametamey SM. Assessment of hypoxia and perfusion in human brain tumors using PET with $18 \mathrm{~F}-$ fluoromisonidazole and 15O-H2O. J Nucl Med Off Publ Soc Nucl Med. (2004) 45:1851-9.
160. Cher LM, Murone C, Lawrentschuk N, Ramdave S, Papenfuss A, Hannah A, et al. Correlation of hypoxic cell fraction and angiogenesis with glucose metabolic rate in gliomas using 18F-fluoromisonidazole, 18F-FDG PET, and immunohistochemical studies. J Nucl Med Off Publ Soc Nucl Med. (2006) 47:410-8.

161. Swanson KR, Chakraborty G, Wang CH, Rockne R, Harpold HLP, Muzi M, et al. Complementary but distinct roles for MRI and 18F-fluoromisonidazole PET in the assessment of human glioblastomas. J Nucl Med Off Publ Soc Nucl Med. (2009) 50:36-44. doi: 10.2967/jnumed.108.055467

162. Hirata K, Terasaka S, Shiga T, Hattori N, Magota K, Kobayashi H, et al. ${ }^{18} \mathrm{~F}$-Fluoromisonidazole positron emission tomography may differentiate glioblastoma multiforme from less malignant gliomas. Eur J Nucl Med Mol Imaging. (2012) 39:760-70. doi: 10.1007/s00259-011-2037-0

163. Gerstner ER, Zhang Z, Fink JR, Muzi M, Hanna L, Greco E, et al. ACRIN 6684: assessment of Tumor hypoxia in newly diagnosed glioblastoma Using 18F-FMISO PET and MRI. Clin Cancer Res Off J Am Assoc Cancer Res. (2016) 22:5079-86. doi: 10.1158/1078-0432.CCR-15-2529

164. Spence AM, Muzi M, Swanson KR, O’Sullivan F, Rockhill JK, Rajendran JG, et al. Regional hypoxia in glioblastoma multiforme quantified with [18F]fluoromisonidazole positron emission tomography before radiotherapy: correlation with time to progression and survival. Clin Cancer Res Off J Am Assoc Cancer Res. (2008) 14:2623-30. doi: 10.1158/1078-0432.CCR-07-4995

165. Toyonaga T, Yamaguchi S, Hirata K, Kobayashi K, Manabe O, Watanabe $\mathrm{S}$, et al. Hypoxic glucose metabolism in glioblastoma as a potential prognostic factor. Eur J Nucl Med Mol Imaging. (2017) 44:611-9. doi: 10.1007/s00259-016-3541-z

166. Belloli S, Brioschi A, Politi LS, Ronchetti F, Calderoni S, Raccagni I, et al. Characterization of biological features of a rat F98 GBM model: a PET-MRI study with [18F]FAZA and [18F]FDG. Nucl Med Biol. (2013) 40:831-40. doi: 10.1016/j.nucmedbio.2013.05.004

167. Horsman MR, Mortensen LS, Petersen JB, Busk M, Overgaard J. Imaging hypoxia to improve radiotherapy outcome. Nat Rev Clin Oncol. (2012) 9:674-87. doi: 10.1038/nrclinonc.2012.171

168. Carlin S, Humm JL. PET of hypoxia: current and future perspectives. I Nucl Med Off Publ Soc Nucl Med. (2012) 53:1171-4. doi: 10.2967/jnumed.111.099770

169. Sharma A, McConathy J. Overview of PET Tracers for brain tumor Imaging. PET Clin. (2013) 8:129-46. doi: 10.1016/j.cpet.2013.02.001

170. Giesel FL, Will L, Lawal I, Lengana T, Kratochwil C, Vorster M, et al. Intraindividual comparison of 18F-PSMA-1007 and 18F-DCFPyL PET/CT in the prospective evaluation of patients with newly diagnosed prostate carcinoma: a pilot Study. J Nucl Med Off Publ Soc Nucl Med. (2018) 59:107680. doi: $10.2967 /$ jnumed.117.204669

171. Afshar-Oromieh A, Zechmann CM, Malcher A, Eder M, Eisenhut M, Linhart HG, et al. Comparison of PET imaging with a (68)Ga-labelled PSMA ligand and (18)F-choline-based PET/CT for the diagnosis of recurrent prostate cancer. Eur J Nucl Med Mol Imaging. (2014) 41:11-20. doi: 10.1007/s00259-013-2525-5

172. Afshar-Oromieh A, Avtzi E, Giesel FL, Holland-Letz T, Linhart HG, Eder $\mathrm{M}$, et al. The diagnostic value of PET/CT imaging with the (68)Ga-labelled PSMA ligand HBED-CC in the diagnosis of recurrent prostate cancer. Eur J Nucl Med Mol Imaging. (2015) 42:197-209. doi: 10.1007/s00259-014-2949-6

173. Afshar-Oromieh A, Holland-Letz T, Giesel FL, Kratochwil C, Mier W, Haufe S, et al. Diagnostic performance of 68Ga-PSMA-11 (HBED-CC) PET/CT in patients with recurrent prostate cancer: evaluation in 1007 patients. Eur J Nucl Med Mol Imaging. (2017) 44:1258-68. doi: 10.1007/s00259-017-3711-7

174. Fendler WP, Eiber M, Beheshti M, Bomanji J, Ceci F, Cho S, et al. 68GaPSMA PET/CT: joint EANM and SNMMI procedure guideline for prostate cancer imaging: version 1.0. Eur J Nucl Med Mol Imaging. (2017) 44:1014-24. doi: 10.1007/s00259-017-3670-z

175. Hope TA, Aggarwal R, Chee B, Tao D, Greene KL, Cooperberg MR, et al. Impact of 68Ga-PSMA-11 PET on management in patients with biochemically recurrent prostate cancer. J Nucl Med Off Publ Soc Nucl Med. (2017) 58:1956-61. doi: 10.2967/jnumed.117.192476

176. Silver DA, Pellicer I, Fair WR, Heston WD, Cordon-Cardo C. Prostatespecific membrane antigen expression in normal and malignant human tissues. Clin Cancer Res Off J Am Assoc Cancer Res. (1997) 3:81-5. 
177. Chang SS, O'Keefe DS, Bacich DJ, Reuter VE, Heston WD, Gaudin PB. Prostate-specific membrane antigen is produced in tumor-associated neovasculature. Clin Cancer Res OffJ Am Assoc Cancer Res. (1999) 5:2674-81.

178. Chang SS, Reuter VE, Heston WD, Bander NH, Grauer LS, Gaudin PB. Five different anti-prostate-specific membrane antigen (PSMA) antibodies confirm PSMA expression in tumor-associated neovasculature. Cancer Res. (1999) 59:3192-8.

179. Mahzouni P, Shavakhi M. Prostate-Specific membrane antigen expression in neovasculature of glioblastoma Multiforme. Adv Biomed Res. (2019) 8:18. doi: 10.4103/abr.abr_209_18

180. Wernicke AG, Edgar MA, Lavi E, Liu H, Salerno P, Bander NH, et al. Prostate-specific membrane antigen as a potential novel vascular target for treatment of glioblastoma multiforme. Arch Pathol Lab Med. (2011) 135:1486-9. doi: 10.5858/arpa.2010-0740-OA

181. Nomura N, Pastorino S, Jiang P, Lambert G, Crawford JR, Gymnopoulos $\mathrm{M}$, et al. Prostate specific membrane antigen (PSMA) expression in primary gliomas and breast cancer brain metastases. Cancer Cell Int. (2014) 14:26. doi: 10.1186/1475-2867-14-26

182. Conway RE, Petrovic N, Li Z, Heston W, Wu D, Shapiro LH. Prostatespecific membrane antigen regulates angiogenesis by modulating integrin signal transduction. Mol Cell Biol. (2006) 26:5310-24. doi: 10.1128/MCB.00084-06

183. Gordon IO, Tretiakova MS, Noffsinger AE, Hart J, Reuter VE, Al-Ahmadie HA. Prostate-specific membrane antigen expression in regeneration and repair. Mod Pathol Off J U S Can Acad Pathol Inc. (2008) 21:1421-7. doi: 10.1038/modpathol.2008.143

184. Sheikhbahaei S, Afshar-Oromieh A, Eiber M, Solnes LB, Javadi MS, Ross $\mathrm{AE}$, et al. Pearls and pitfalls in clinical interpretation of prostate-specific membrane antigen (PSMA)-targeted PET imaging. Eur J Nucl Med Mol Imaging. (2017) 44:2117-36. doi: 10.1007/s00259-017-3780-7

185. Hofman MS, Hicks RJ, Maurer T, Eiber M. Prostate-specific Membrane Antigen PET: clinical utility in prostate cancer, normal patterns, pearls, and Pitfalls. Radiogr Rev Publ Radiol Soc N Am Inc. (2018) 38:200-17. doi: 10.1148/rg.2018170108

186. Kunikowska J, Bartosz K, Leszek K. Glioblastoma multiforme: another potential application for 68Ga-PSMA PET/CT as a guide for targeted therapy. Eur J Nucl Med Mol Imaging. (2018) 45:886-7. doi: 10.1007/s00259-018-3934-2

187. Schwenck J, Tabatabai G, Skardelly M, Reischl G, Beschorner R, Pichler $\mathrm{B}$, et al. In vivo visualization of prostate-specific membrane antigen in glioblastoma. Eur J Nucl Med Mol Imaging. (2015) 42:170-1. doi: 10.1007/s00259-014-2921-5

188. Salas Fragomeni RA, Menke JR, Holdhoff M, Ferrigno C, Laterra JJ, Solnes LB, et al. Prostate-Specific membrane antigen-targeted imaging with [18F]DCFPyL in high-grade Gliomas. Clin Nucl Med. (2017) 42:e433-5. doi: 10.1097/RLU.0000000000001769

189. Sasikumar A, Joy A, Pillai MRA, Nanabala R, Anees K M, Jayaprakash PG, et al. Diagnostic value of 68Ga PSMA-11 PET/CT imaging of brain tumors-preliminary analysis. Clin Nucl Med. (2017) 42:e41-8. doi: 10.1097/RLU.0000000000001451

190. Salas Fragomeni RA, Pienta KJ, Pomper MG, Gorin MA, Rowe SP. Uptake of Prostate-specific membrane antigen-targeted 18F-DCFPyL in cerebral radionecrosis: implications for diagnostic imaging of high-grade Gliomas. Clin Nucl Med. (2018) 43:e419-21. doi: 10.1097/RLU.0000000000002280

191. Verma P, Malhotra G, Goel A, Rakshit S, Chandak A, Chedda R, et al. Differential Uptake of 68Ga-PSMA-HBED-CC (PSMA-11) in low-grade versus high-grade gliomas in treatment-naive Patients. Clin Nucl Med. (2019) 44:e318-22. doi: 10.1097/RLU.0000000000002520

192. Sasikumar A, Kashyap R, Joy A, Charan Patro K, Bhattacharya P, Reddy Pilaka VK, et al. Utility of 68Ga-PSMA-11 PET/CT in Imaging of glioma-a pilot Study. Clin Nucl Med. (2018) 43:e304-9. doi: 10.1097/RLU.0000000000002175

193. Backhaus P, Noto B, Avramovic N, Grubert LS, Huss S, Bögemann M, et al. Targeting PSMA by radioligands in non-prostate disease-current status and future perspectives. Eur J Nucl Med Mol Imaging. (2018) 45:860-77. doi: 10.1007/s00259-017-3922-y

194. Matsuda M, Ishikawa E, Yamamoto T, Hatano K, Joraku A, Iizumi Y, et al. Potential use of prostate specific membrane antigen (PSMA) for detecting the tumor neovasculature of brain tumors by PET imaging with 89Zr-Df-IAB2M anti-PSMA minibody. J Neurooncol. (2018) 138:581-9. doi: 10.1007/s11060-018-2825-5

195. Lapa C, Linsenmann T, Lückerath K, Samnick S, Herrmann K, Stoffer C, et al. Tumor-associated macrophages in glioblastoma multiforme-a suitable target for somatostatin receptor-based imaging and therapy? PLoS ONE. (2015) 10:e0122269. doi: 10.1371/journal.pone.0122269

196. Collamati F, Pepe A, Bellini F, Bocci V, Chiodi G, Cremonesi M, et al. Toward radioguided surgery with $\beta$ - decays: uptake of a somatostatin analogue, DOTATOC, in meningioma and high-grade glioma. J Nucl Med Off Publ Soc Nucl Med. (2015) 56:3-8. doi: 10.2967/jnumed.114.145995

197. Alkonyi B, Barger GR, Mittal S, Muzik O, Chugani DC, Bahl G, et al. Accurate differentiation of recurrent gliomas from radiation injury by kinetic analysis of $\alpha$-11C-methyl-L-tryptophan PET. J Nucl Med Off Publ Soc Nucl Med. (2012) 53:1058-64. doi: 10.2967/jnumed.111.097881

198. Kamson DO, Mittal S, Robinette NL, Muzik O, Kupsky WJ, Barger GR, et al. Increased tryptophan uptake on PET has strong independent prognostic value in patients with a previously treated high-grade glioma. Neuro Oncol. (2014) 16:1373-83. doi: 10.1093/neuonc/nou042

199. Kondo A, Ishii H, Aoki S, Suzuki M, Nagasawa H, Kubota K, et al. Phase IIa clinical study of $[18 \mathrm{~F}]$ fluciclovine: efficacy and safety of a new PET tracer for brain tumors. Ann Nucl Med. (2016) 30:608-18. doi: 10.1007/s12149-016-1102-y

200. Venneti S, Dunphy MP, Zhang H, Pitter KL, Zanzonico P, Campos $\mathrm{C}$, et al. Glutamine-based PET imaging facilitates enhanced metabolic evaluation of gliomas in vivo. Sci Transl Med. (2015) 7:274ra17. doi: 10.1126/scitranslmed.aaa1009

201. Su Z, Roncaroli F, Durrenberger PF, Coope DJ, Karabatsou K, Hinz R, et al. The $18-\mathrm{kDa}$ mitochondrial translocator protein in human gliomas: an $11 \mathrm{C}$ (R)PK11195 PET imaging and neuropathology study. J Nucl Med Off Publ Soc Nucl Med. (2015) 56:512-7. doi: 10.2967/jnumed.114.151621

202. Winkeler A, Boisgard R, Awde AR, Dubois A, Thézé B, Zheng J, et al. The translocator protein ligand $\left[{ }^{18} \mathrm{~F}\right] \mathrm{DPA}-714$ images glioma and activated microglia in vivo. Eur J Nucl Med Mol Imaging. (2012) 39:811-23. doi: 10.1007/s00259-011-2041-4

203. Albert NL, Unterrainer M, Fleischmann DF, Lindner S, Vettermann F, Brunegraf A, et al. TSPO PET for glioma imaging using the novel ligand 18F-GE-180: first results in patients with glioblastoma. Eur J Nucl Med Mol Imaging. (2017) 44:2230-8. doi: 10.1007/s00259-017-3799-9

204. Strauss LG, Koczan D, Seiz M, Tuettenberg J, Schmieder K, Pan L, et al. Correlation of the Ga-68-bombesin analog Ga-68-BZH3 with receptors expression in gliomas as measured by quantitative dynamic positron emission tomography (dPET) and gene arrays. Mol Imaging Biol MIB Off Publ Acad Mol Imaging. (2012) 14:376-83. doi: 10.1007/s11307-011-0508-0

205. Zhang J, Li D, Lang L, Zhu Z, Wang L, Wu P, et al. 68Ga-NOTA-Aca-BBN(714) PET/CT in healthy volunteers and glioma patients. J Nucl Med Off Publ Soc Nucl Med. (2016) 57:9-14. doi: 10.2967/jnumed.115.165316

206. Tateishi K, Tateishi U, Sato M, Yamanaka S, Kanno H, Murata H, et al. Application of 62Cu-diacetyl-bis (N4-methylthiosemicarbazone) PET imaging to predict highly malignant tumor grades and hypoxia-inducible factor-1 $\alpha$ expression in patients with glioma. AJNR Am J Neuroradiol. (2013) 34:92-9. doi: 10.3174/ajnr.A3159

207. Yamamoto Y, Nishiyama Y, Kimura N, Kameyama R, Kawai N, Hatakeyama $\mathrm{T}$, et al. 11C-acetate PET in the evaluation of brain glioma: comparison with 11C-methionine and 18F-FDG-PET. Mol Imaging Biol MIB Off Publ Acad Mol Imaging. (2008) 10:281-7. doi: 10.1007/s11307-008-0152-5

208. Li D, Zhao X, Zhang L, Li F, Ji N, Gao Z, et al. (68)Ga-PRGD2 PET/CT in the evaluation of Glioma: a prospective study. Mol Pharm. (2014) 11:3923-9. doi: $10.1021 / \mathrm{mp} 5003224$

209. Oborski MJ, Laymon CM, Lieberman FS, Qian Y, Drappatz J, Mountz JM. [18F]ML-10 PET: initial Experience in glioblastoma multiforme therapy response Assessment. Tomography. (2016) 2:317-24. doi: $10.18383 /$ j.tom. 2016.00175

210. Tsuchida T, Takeuchi H, Okazawa H, Tsujikawa T, Fujibayashi Y. Grading of brain glioma with 1-11C-acetate PET: comparison with 18F-FDG PET. Nucl Med Biol. (2008) 35:171-6. doi: 10.1016/j.nucmedbio.2007.11.004

211. Schnell O, Krebs B, Carlsen J, Miederer I, Goetz C, Goldbrunner $\mathrm{RH}$, et al. Imaging of integrin alpha(v)beta(3) expression in patients 
with malignant glioma by [18F] Galacto-RGD positron emission tomography. Neuro Oncol. (2009) 11:861-70. doi: 10.1215/152285172009-024

212. Zhang H, Liu N, Gao S, Hu X, Zhao W, Tao R, et al. Can an ${ }^{18}$ F-ALFNOTA-PRGD2 PET/CT Scan Predict treatment sensitivity to concurrent chemoradiotherapy in patients with newly diagnosed Glioblastoma? J Nucl Med Off Publ Soc Nucl Med. (2016) 57:524-9. doi: 10.2967/jnumed.115. 165514

213. Langen K-J, Galldiks N, Hattingen E, Shah NJ. Advances in neurooncology imaging. Nat Rev Neurol. (2017) 13:279-89. doi: 10.1038/nrneurol. 2017.44
Conflict of Interest: The authors declare that the research was conducted in the absence of any commercial or financial relationships that could be construed as a potential conflict of interest.

Copyright (๑) 2019 Moreau, Febvey, Mognetti, Frappaz and Kryza. This is an openaccess article distributed under the terms of the Creative Commons Attribution License (CC BY). The use, distribution or reproduction in other forums is permitted, provided the original author(s) and the copyright owner(s) are credited and that the original publication in this journal is cited, in accordance with accepted academic practice. No use, distribution or reproduction is permitted which does not comply with these terms. 